HENRIQUE WENDLING SAVA

\title{
Avaliação morfológica da invasão da cartilagem tireoide no tumor precoce de andar glótico acometendo a comissura anterior
}

Dissertação apresentada à Faculdade de Medicina da Universidade de São Paulo para obtenção do Título de Mestre em Ciências.

Curso de Pós-graduação de Fisiopatologia Experimental

São Paulo

2016 
HENRIQUE WENDLING SAVA

\section{Avaliação morfológica da invasão da cartilagem tireoide no tumor precoce de andar glótico acometendo a comissura anterior}

Dissertação apresentada à Faculdade de Medicina da Universidade de São Paulo para obtenção do Título de Mestre em Ciências.

Curso de Pós-graduação de Fisiopatologia Experimental

Orientador: Prof. Dr. Rogério Aparecido Dedivitis

São Paulo

2016 
Dados Internacionais de Catalogação na Publicação (CIP)

Preparada pela Biblioteca da

Faculdade de Medicina da Universidade de São Paulo

Creprodução autorizada pelo autor

Sava, Henrique Wendling Sava

Avaliação morfológica da invasão da cartilagem tireoide no tumor precoce de andar glótico acometendo a comissura anterior / Henrique Wendling Sava. -- São Paulo, 2016.

Dissertação(mestrado)--Faculdade de Medicina da Universidade de São Paulo.

Programa: Fisiopatologia Experimental

Orientador: Prof. Dr. Rogério Aparecido Dedivitis

Descritores: 1.Laringectomia 2.Carcinoma de Células Escamosas 3.Neoplasias Laríngeas 4. Laringe 
A Deus, pela vida, por sempre estar comigo em minha caminhada. A minha esposa Fernanda, por sempre me apoiar, motivar e compreender os momentos de ausência para a realização deste trabalho. A meus pais, Luiz Carlos e Jussara. 


\section{AGRADECIMENTOS}

Aos pacientes envolvidos neste estudo, razão pela qual desenvolvemos a ciência na esperança de melhor entendermos a doença.

Ao Prof. Dr. Rogério A. Dedivitis, meu orientador, agradeço a paciência e atenção na confecção desta dissertação.

Ao Dr. Angelo Sementilli, pela colaboração ao realizar ao fotomicrografias para a documentação dos casos.

Ao Dr. Ricardo Camillo de Almeida, pela reavaliação das lâminas de histopatologia.

Ao Dra. Cláudia Kliemann, pela avaliação das lâminas dos casos novos do Hospital das Clínicas.

À Dra. Inês Nishimoto, pelo tratamento estatístico que proporcionou ao material de nosso estudo, com interesse, competência e prontidão.

Aos membros da comissão julgadora do exame de qualificação: Profa. Dra. Vera Luíza Capelozzi, Prof. Dr. Cláudio Roberto Cernea e Prof. Dr. Marco Aurélio Vamondes Kulcsar, titulares; e Prof. Dr. Chao Lung Wen e Prof. Dr. Leandro Luongo de Matos, suplentes; pela disponibilidade em avaliar, corrigir e sugerir.

Aos secretários Igor Tolgyesi e Vanda Mariscal, do Curso de PósGraduação de Fisiopatologia Experimental, pela permanente disponibilidade. 


\section{LISTA DE FIGURAS}

Figura 1 - Aspecto macroscópico de um espécime ..................................... 33

Figura 2 - Transição normal. ............................................................. 45

Figura 3 - Tumor adjacente à cartilagem ............................................. 46

Figura 4 - Invasão pericondrial da cartilagem tireoide ............................... 47

Figura 5 - Invasão pericondrial da cartilagem tireoide. ............................. 48

Figura 6 - Invasão da cartilagem tireoide na região central com

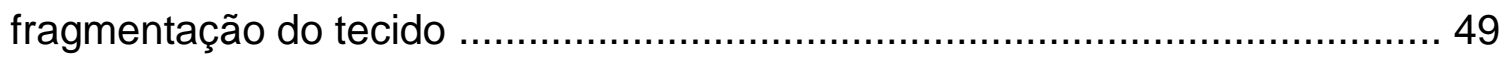

Figura 7 - Presença de irregularidade moderada, sem evidência

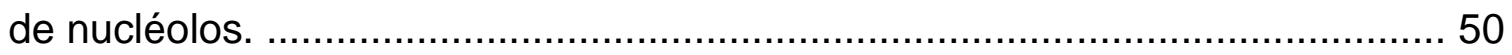

Figura 8 - Presença de irregularidade intensa e evidência de nucléolos. ........ 50

Figura 9 - Presença de necrose tumoral. ..................................................... 51

Figura 10 - Presença de necrose tumoral superficial. .................................. 51

Figura 11 - Manutenção do arranjo de elastina. ........................................... 52

Figura 12 - Perda da elastina. .............................................................. 52 


\section{LISTA DE TABELAS}

Tabela 1 - Distribuição da casuística de acordo com variáveis demográficas e clínicas dos 48 pacientes.

Tabela 2 - Distribuição da casuística de acordo com variáveis patológicas dos 48 pacientes.

Tabela 3 - Distribuição das variáveis demográficas e clínicas de acordo com condição da comissura anterior dos 48 pacientes.

Tabela 4 - Distribuição das variáveis patológicas de acordo com condição da comissura anterior dos 48 pacientes. 55

Tabela 5 - Distribuição das variáveis demográficas e clínicas de acordo com condição da comissura anterior dos 48 pacientes.

Tabela 6 - Distribuição das variáveis patológicas de acordo com a condição da comissura anterior dos 48 pacientes. 


\section{LISTA DE GRÁFICOS}

Gráfico 1 - Distribuição do status da comissura anterior pela idade. .............. 58

Gráfico 2 - Distribuição do status da comissura anterior pelo tempo

de história.

58

Gráfico 3 - Distribuição do status da comissura anterior pela localização da

lesão.

59

Gráfico 4 - Distribuição do status da comissura anterior pelo estádio T. ......... 59

Gráfico 5 - Distribuição do status da comissura anterior pela idade. .............. 60

Gráfico 6 - Distribuição do status da comissura anterior pela idade. .............. 60

Gráfico 7 - Distribuição do status da comissura anterior pela localização da

lesão.

61

Gráfico 8 - Distribuição do status da comissura anterior pelo estádio T. ......... 61 


\title{
LISTA DE ABREVIAÇÕES
}

\author{
RT - Radioterapia \\ MEL - microrressecção endoscópica à laser \\ T - Estádio tumoral \\ EVPL - Laringectomia parcial vertical endoscópica \\ TC - Tomografia computadorizada \\ HE - Hematoxilina-eosina \\ ADN - ácido desoxirribonucleico \\ ARN - ácido ribonucléico
}




\section{RESUMO}

Sava HW. Avaliação morfológica da invasão da cartilagem tireoide no tumor precoce de andar glótico acometendo a comissura anterior. São Paulo: "Faculdade de Medicina, Universidade de São Paulo"; 2016.

Introdução: A comissura anterior constitui-se em área de infiltração do câncer

glótico, mesmo em estádio precoce. Objetivo: Avaliar o acometimento por tumor da cartilagem da comissura anterior em espécimes de laringectomia frontolateral. Métodos: Foram incluídos 48 pacientes submetidos à laringectomia frontolateral por carcinoma espinocelular T1b/T2. Aspectos epidemiológicos, clínicos e análise morfológica histopatológica foram avaliados. Resultados: Quarenta e dois pacientes (87,5\%) tinham lesões T1b e seis (12,5\%), T2. Trinta e quatro casos $(70,8 \%)$ apresentaram tecido sadio entre o tumor e a cartilagem tireoidea, 10 casos $(20,8 \%)$ tinham tumor contíguo à cartilagem e, em quatro casos $(8,3 \%)$, houve invasão da cartilagem. Não houve maior risco de desfecho adverso nos grupos com infiltração ou tumor adjacente à cartilagem. Grau de diferenciação, índice mitótico, irregularidade nuclear, presença de nucléolo e necrose tumoral não tiveram relação com invasão da cartilagem. Conclusão: A infiltração da cartilagem tireoidea ocorreu em 8,3\% dos tumores e não mudou o desfecho em pacientes submetidos à laringectomia fronto-lateral. As características morfológicas não apresentaram significado estatístico.

Descritores: Laringectomia. Carcinoma de Células Escamosas. Neoplasias Laríngeas. Laringe. Cartilagem Tireoide. 


\begin{abstract}
Sava HW. Morphologic evaluation of invasion of the thyroid cartilage in early glottic tumor spreading to the anterior commissure. São Paulo: "Faculdade de Medicina, Universidade de São Paulo"; 2016.

Introduction: The anterior commissure is an area of glottic cancer infiltration, even in early stages. Objective: To evaluate the involvement of cartilage by the tumor of the anterior commissure in surgical specimens of frontolateral laryngectomy. Methods: 48 patients who had undergone frontolateral laryngectomy for $\mathrm{T} 1 \mathrm{~b} / \mathrm{T} 2$ squamous cell carcinoma were included.

Epidemiological and clinical aspects as well as morphological histopathological analysis were evaluated. Results: 42 patients $(87,5 \%)$ had T1b lesions and 6 $(12,5 \%)$ had T2. Thirty-four cases $(70,8 \%)$ showed healthy tissue between the tumor and thyroid cartilage, 10 cases $(20,8 \%)$ had a tumor contiguous with cartilage; and in 4 cases $(8,3 \%)$ there was cartilage invasion. There was no major risk of adverse closure in the groups with the infiltration or tumor adjacent to cartilage. Grade of cellular differentiation, mitotic index, nuclear irregularity, the presence of nucleolus and tumoral necrosis were not related to cartilage invasion. Conclusion: the infiltration of thyroid cartilage occurred in $8,3 \%$ of tumors and did not change the outcome in patients submitted to partial frontolateral laryngectomy. The morphological characteristics did not show any statistical significance.
\end{abstract}

Key words: Laryngectomy. Carcinoma, Squamous Cell. Laryngeal Neoplasms. Larynx. Thyroid Cartilage. 
Essa tese está de acordo com as seguintes normas, em vigor no momento desta publicação:

Referências: adaptado de International Committee of Medical Journals Editors (Vancouver).

Universidade de São Paulo. Faculdade de Medicina. Divisão de Biblioteca e Documentação. Guia de apresentação de dissertações, teses e monografias. Elaborado por Anneliese Carneiro da Cunha, Maria Julia de A. L. Freddi, Maria F. Crestana, Marinalva de Souza Aragão, Suely Campos Cardoso, Valéria Vilhena. $3^{\text {a }}$ ed. São Paulo: Divisão de Biblioteca e Documentação; 2011.

Abreviaturas dos títulos dos periódicos de acordo com List of Journals Indexed in Index Medicus. 


\section{SUMÁRIO}

Lista de figuras

Lista de tabelas

Lista de gráficos

Lista de abreviações

Resumo

Abstract

Sumário

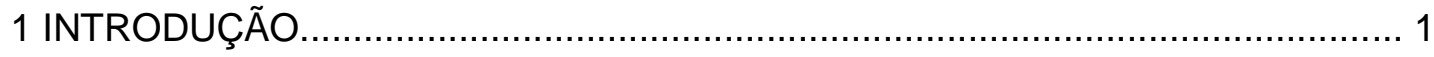

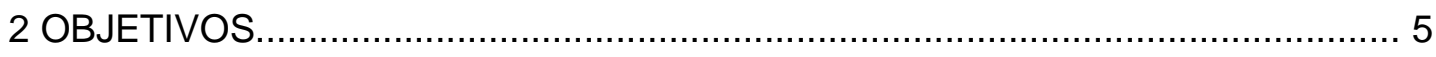

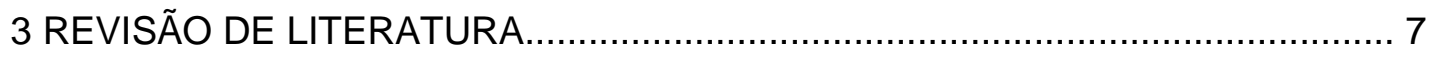

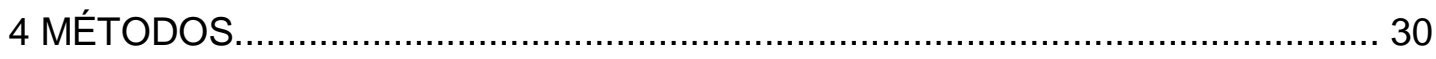

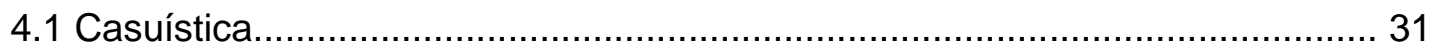

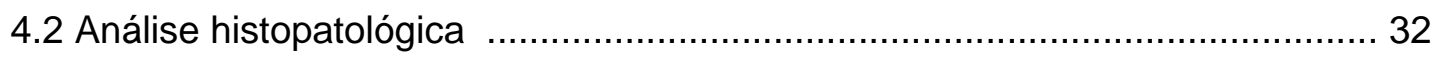

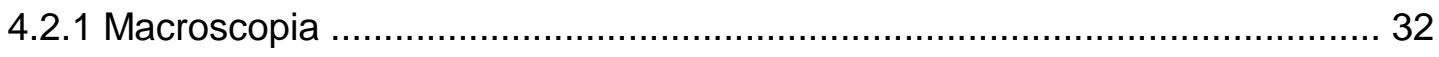

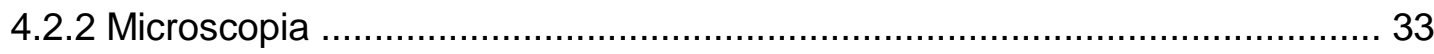

4.2.3 Aspectos epidemiológicoa e clínicos ..................................................... 38

4.3 Análise estatística ....................................................................... 39

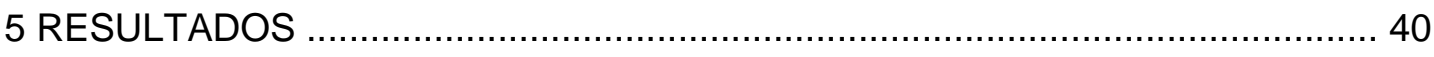

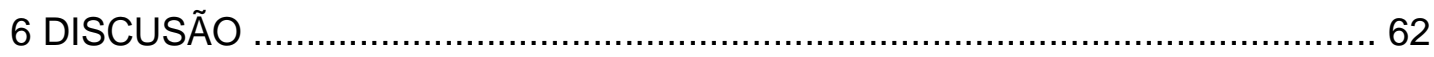

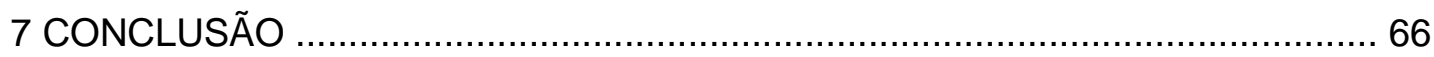

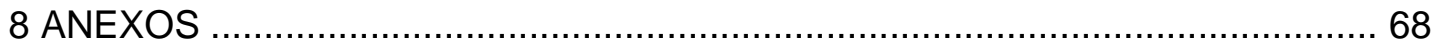

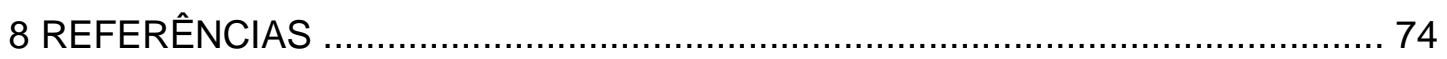


1 INTRODUÇÃO 


\section{INTRODUÇÃO}

A laringe é um órgão de estrutura singular que desenvolve funções complexas, como respiração, prevenção da aspiração, deglutição e fonação. A laringe é dividida, anatomicamente, em três andares: supraglótico, glótico e infraglótico. Esses compartimentos estão limitados por membranas e cartilagens, sendo que essas estruturas atuam como limites para o crescimento de tumores no estádio inicial ${ }^{1}$.

A comissura anterior constitui-se em um dos locais de grande interesse oncológico. Situa-se na linha média, no ponto em que ocorre a inserção das pregas vocais, sendo formada por tecido conjuntivo. Esse tecido forma uma proteção inicial contra a invasão profunda de neoplasias, fazendo com que, em fases iniciais, haja uma propagação ao longo da mucosa ${ }^{2,3}$. Apesar disso, o ponto mais fraco da estrutura laríngea é a linha média. Isso ocorre devido a não haver tecido pericondrial nesse local, tornando-o mais suscetível à invasão da cartilagem pelo câncer ${ }^{4}$. Assim, em carcinomas de células escamosas glóticos mais avançados, a invasão da cartilagem tireoide geralmente se dá na comissura anterior e, com isso, acaba espalhando-se para fora da laringe ${ }^{5}$. 
Câncer da laringe pode ser tratado tanto por cirurgia como por radioterapia $(\mathrm{RT})$ e isso se aplica às neoplasias precoces que acometem a comissura anterior ${ }^{6}$. Em pacientes com carcinoma de laringe submetido à $\mathrm{RT}$, pode ser notada uma pior taxa de controle local quando há invasão da comissura anterior ${ }^{7,8}$. Assim, a invasão de comissura anterior pode ser considerada um preditor de má resposta à $R T^{9}$.

Por outro lado, alguns estudos mostram que pode não haver relação entre o acometimento de comissura anterior e a falha no tratamento radioterápico ${ }^{10,11}$. Os casos de câncer precoce acometendo a comissura anterior com má resposta à $\mathrm{RT}$ podem ser tratados com laringectomia parcial de resgate ${ }^{12}$.

A outra modalidade que pode ser usada no tratamento de pacientes com câncer precoce de laringe que acomete comissura anterior é a operação. Classicamente, o procedimento utilizado é a laringectomia frontolateral, técnica em que o espécime cirúrgico inclui a prega vocal acometida junto com a comissura anterior, a porção mediana da cartilagem tireoide e parte da prega vocal contralateral. Por incluir parte da cartilagem dentro da margem cirúrgica, este pode ser considerado procedimento de escolha nesses casos. Assim, pode-se conseguir uma ressecção oncologicamente segura e mantendo as funções da laringe ${ }^{13,14}$. 
A avaliação do acometimento da cartilagem tireoide pelo câncer na comissura anterior, mostrando a ocorrência de sua invasão, pode indicar o quanto podem ser seguros os tratamentos que poupam a cartilagem (microcirurgia e RT), permitindo ou não um maior uso dessas técnicas nos casos de pacientes com carcinoma precoce de laringe com acometimento de comissura anterior. 
2 OBJETIVO 


\section{OBJETIVO}

Avaliar o acometimento por câncer da cartilagem da comissura anterior em espécimes cirúrgicos de laringectomias frontolaterais, correlacionando-as com dados clínicos e patológicos do paciente. 
3 REVISÃO DA LITERATURA 


\section{REVISÃO DA LITERATURA}

A laringe foi descrita primeiramente por Hipócrates, por volta do ano 300 a.C. e constitui-se no órgão que comunica a faringe com a traqueia. É constituída por cartilagens, unidas entre si por membranas e ligamentos e movimentadas por ações musculares, sendo coberta internamente por mucosa ${ }^{15}$.

Em 1891, Hajek, por meio de estudos anatômicos, demonstrou que a laringe é dividida em três compartimentos distintos: supraglótico, glótico e infraglótico. Demonstrou ainda que esses compartimentos possuem diferenças estruturais e funcionais que os tornam bastantes distintos entre si. Verificou que as pregas vocais inserem-se em um ponto na linha média, que denominou comissura anterior $^{16}$.

Broyles, em 1943, demonstrou que, na linha média, na altura da inserção das pregas vocais, somente uma corda fibrosa separa a mucosa da cartilagem. Isso foi chamado de tendão da comissura anterior. $\mathrm{Na}$ inserção do tendão, a cartilagem tireoide não possui pericôndrio interno, o que diminuiria a resistência à invasão neoplásica. Assim, este seria o ponto mais propenso à invasão neoplásica da cartilagem tireoide ${ }^{17}$. 
Em 1956, Pressman et al., estudando a estrutura da laringe, descobriram que os compartimentos da laringe são separados entre si por barreiras de tecido conjuntivo. Dentre estas, estão as zonas transicionais entre as regiões glótica e supraglótica e a comissura anterior $^{18}$.

Realizando em 1962 um estudo com secção de laringe, Tucker et al. demonstraram que os compartimentos e barreiras afetam o crescimento de tumores na laringe e que essas barreiras de tecido conjuntivo podem servir como barreiras para 0 crescimento do câncer, no seu início ${ }^{19}$. Isso foi comprovado por Kirchner $^{20}$ e Olofsson e van Nostrand ${ }^{21}$.

Assim, a comissura anterior ganhou grande importância oncológica. Isso se deve ao fato de que, além de constituir-se de uma barreira inicial ao crescimento neoplásico, ela é o local de mais fácil penetração na cartilagem tireoidea ${ }^{22}$.

A laringectomia frontolateral foi descrita por Leroux-Robert, em 1956, visando permitir a ressecção da prega vocal e da comissura anterior, juntamente com a quilha da cartilagem tireoide. Essa operação é indicada para neoplasias glóticas iniciais acometendo pregas vocais e comissura anterior ${ }^{23}$. Por muitos anos, esse procedimento permaneceu como sendo o tratamento padrão nesses $\operatorname{casos}^{13,14,24}$. 
Som e Silver, em 1968, apresentaram taxas de cura de $81 \%$ com o uso de laringectomia parcial frontolateral em casos de tumores glóticos precoces com invasão de comissura anterior ${ }^{25}$.

Em 1970, Kirchner apresentou um importante estudo envolvendo o tratamento radioterápico em pacientes com neoplasia glótica invadindo a comissura anterior. Apresentou uma taxa de controle de doença de $60 \%$, com uma taxa de sobrevida livre de doença em 5 anos de 25\%. Sugeriu que isso se deve ao fato de a comissura anterior receber menor dose de irradiação, concluindo que a RT não deveria ser o tratamento de escolha para câncer glótico que invade essa estrutura ${ }^{26}$.

No ano seguinte, Jesse et al. publicaram uma série de 106 pacientes tratados com $\mathrm{RT}$, com $8,8 \%$ de falha no tratamento. Com isso, concluíram que a RT pode ser o tratamento de escolha nos casos de tumores glóticos precoces com invasão de comissura anterior $^{27}$. Conclusão semelhante tiveram Olofsson et al., em 1972, encontrando sobrevida de $80 \%$ em 5 anos em estudo semelhante, envolvendo 57 pacientes ${ }^{22}$. Nesses estudos, os autores conseguiram resultados comparáveis àqueles atingidos por meio de operação.

No final da década de 70, uma nova modalidade terapêutica estava sendo criada para os cânceres de laringe. A 
microrressecção endoscópica à laser (MEL) foi desenvolvida em estudos de Strong ${ }^{28}$, Jako et al. ${ }^{29}$ e Vaughan ${ }^{30}$. Steiner, em 1981, começou a utilizar esse tipo de procedimento para o tratamento de neoplasias envolvendo a comissura anterior ${ }^{31}$. Diferentemente do que é realizado na laringectomia frontolateral, na MEL, a porção anterior da cartilagem tireoide não é ressecada, podendo ser um fator de risco à recidiva neoplásica.

Em 1981, Bagatella e Bignardi, seccionando 60 laringes de pessoas adultas sem câncer, definiram um espaço de 1,5 a 2mm localizado entre o ângulo da cartilagem tireoide e a mucosa laríngea no nível da comissura anterior. Esse espaço, definido pelos autores como "espaço X", é composto de tecido conectivo, não possuindo vasos sanguíneos ou linfáticos. Descreveram esse local como uma barreira à progressão do câncer da supraglote para a glote e entre os dois lados da glote ${ }^{2}$. Em outro estudo, envolvendo laringes com câncer, os mesmos autores demonstraram que, se a mucosa estiver livre à inspeção, não haverá invasão submucosa ou invasão da cartilagem ${ }^{3}$.

Já em 1982, Yeager e Archer mostraram que o pericôndrio funciona como uma barreira ao crescimento de cânceres muito mais eficaz do que a própria cartilagem ou osso. Com isso, reafirmaram a 
importância da comissura anterior como ponto mais provável de invasão em cartilagem por um câncer na laringe ${ }^{1}$.

Em 1996, Rucci et al. estudaram o desenvolvimento da região da comissura anterior por meio de secções seriadas de laringes de embriões, fetos e adultos. Nesse estudo, observaram que as estruturas nessa região derivam de uma banda mesenquimal, inicialmente evidente com sete semanas de gestação, entre as lâminas laterais da cartilagem tireoide. Essa banda dá origem a todas as estruturas na linha média da cartilagem. Isso tornou evidente que o tendão de Broyle deriva da parte dorsal do processo mediano e torna-se intimamente conectado com as estruturas vizinhas, incluindo as inserções das fibras dos músculos vocais. Tudo isso demonstra a razão pela qual as neoplasias apresentam características distintas de crescimento quando invadem a comissura anterior $^{32}$. Outra causa, descrita mais tarde no ano de 2000, de facilitação da invasão neoplásica na cartilagem é sua ossificação. Ela ocorre preferencialmente nos pontos de fixação muscular, como no tendão de Broyle. Nessa área de contato, intensifica-se o processo de esclerose e a criação de vasos sanguíneos. Esses vasos criam, assim, uma conexão entre o aporte sanguíneo interno e externo da laringe aumentando a vulnerabilidade à expansão neoplásica ${ }^{33}$. 
Em 1989, Krespi e Meltzer descreveram cinco pacientes com câncer com estádio tumoral (T) T1b glótico (com acometimento de comissura anterior) tratados com MEL. Todos os pacientes apresentaram recorrência local, necessitando de outros procedimentos para resgate ${ }^{34}$. Na época, carcinomas da laringe em outros locais tinham resultados melhores do que os apresentados por eles ${ }^{35,36}$.

Fiorella et al., em 1999, estudaram 150 pacientes que foram submetidos à laringectomia frontolateral. Destes, 14\% tiveram recorrências locais. Revendo os espécimes histopatologicamente, observaram que a infiltração microscópica da comissura anterior estava associada a um maior número de recorrências locais $(25,5 \%$ vs. $5 \%$ ) e a $55 \%$ de sobrevida livre de doença ${ }^{24}$.

Em 2000, Rifai e Khattab realizaram o exame histopatológico da região da comissura anterior em 30 pacientes com carcinoma glótico precoce com acometimento da comissura anterior. Nesse exame, encontrou-se o envolvimento microscópico da cartilagem tireoide nos 30 casos. Com isso, concluíram que, nos casos em que há acometimento da cartilagem tireoide, é mandatória a ressecção da sua porção anterior juntamente com a mucosa acometida, tornando desaconselháveis a RT e a MEL nesses casos ${ }^{37}$. 
No mesmo ano, Nozaki et al. avaliaram 64 pacientes com T1 glótico tratados por meio de RT. Destes, 50 não tinham envolvimento de comissura anterior, enquanto 14 tinham. No primeiro grupo, houve uma taxa de controle local em cinco anos de $89 \%$, enquanto a taxa correspondente no outro grupo foi de $58 \%$. Não houve diferença significativa entre os estádios T1a e T1b. Os autores acreditaram que isso ocorreu pela dificuldade de acesso da terapia à comissura anterior devido a alguns fatores anatômicos, como o formato da cartilagem tireoide, fazendo com que a dose fosse menor nesse local e pelo uso de filtros de proteção para a referida cartilagem para evitar condronecrose, o que poderia diminuir a dose em células neoplásicas que invadiram a cartilagem. Assim, a presença de invasão cartilaginosa pelo câncer diminuiria a resposta local deste à $R T^{38}$.

Por outro lado, Persky et al., no ano de 2000, analisando 35 pacientes com câncer T1-T2 glóticos acometendo comissura anterior e tratados com RT, obtiveram taxa de $88 \%$ de controle local, sendo 93\% em T1 e 60\% em T2. Esses índices foram elevados a 100\% quando associados à operação de resgate. Foi concluído que a RT é um tratamento efetivamente curativo nos casos de câncer T1 glótico envolvendo a comissura anterior. A 
operação de resgate aumentou a sobrevida e o controle em tumores recorrentes ${ }^{39}$.

Peretti et al. em 2000, relataram a MEL em 140 pacientes, incluindo 21 deles com carcinoma in situ, 96 com T1 e 23 com lesões T2. Controle local em 5 anos foi encontrado em $95 \%$ das lesões in situ, $87 \%$ das lesões $\mathrm{T} 1$ e $91 \%$ das lesões T2. Envolvimento da comissura anterior ou prega vestibular e invasão muscular profunda foram associados com piores resultados ${ }^{40}$.

Em 2000, Eckel et al. analisaram a MEL em 285 pacientes. Das 161 neoplasias T1, 18 (11\%) recidivaram a 5 anos e, das 91 neoplasias T2, 15,4\% recidivaram. Dos 35 pacientes com recorrência tumoral, 16 foram submetidos à laringectomia total, 10 foram tratados com nova MEL, em quatro foram realizadas laringectomias parciais e dois foram tratados com RT. Três pacientes não receberam nenhum tratamento ${ }^{41}$.

Já em 2001, Maheshwar e Gaffney, estudando pacientes com câncer T1 glótico, tiveram piores resultados nos pacientes que tinham envolvimento da comissura anterior quando comparados àqueles sem seu envolvimento, mostrando que tal envolvimento piora o prognóstico e aumenta a falha locorregional em pacientes submetidos à RT. Colocaram como razão um provável subestadiamento que estaria ocorrendo já que, com a presença de 
invasão da cartilagem, os tumores estariam em estádio mais avançado que o suspeitado ${ }^{9}$.

Em 2003, Pradhan et al. realizaram MEL para tratar 179 pacientes com carcinoma glótico. Todos os pacientes tinham estadiamento T1a ou T1b, sendo que 14 envolviam uma prega vocal e a comissura anterior e quatro envolviam a comissura anterior e ambas as pregas vocais. Dos 77 pacientes sem envolvimento da comissura anterior, 10 (13\%) tiveram recorrência local e, dentre os pacientes que tinham envolvimento da comissura anterior e uma prega vocal, cinco (35,7\%) tiveram recorrência local. Os autores acreditam que esse mau resultado com os pacientes com envolvimento de comissura anterior aconteceu por causa da dificuldade de exposição adequada da comissura anterior e porque as lesões nessa topografia são frequentemente subestadiadas. $O$ envolvimento da cartilagem tireoide é comumente não visto ou julgado, fazendo com que uma lesão T4 seja tratada como T2, levando a maus resultados. Concluíram que a MEL é uma modalidade terapêutica oncologicamente segura, com taxas de cura semelhantes àquelas conseguidas com RT ou cirurgias convencionais, com exceção de lesões envolvendo a comissura anterior, que devem ser realizadas endoscopicamente somente quando a exposição é adequada e o câncer não é infiltrativo ${ }^{42}$. 
Em contraste com o estudo descrito acima, Pearson e Salassa, em 2003, realizaram um estudo retrospectivo de 39 pacientes com carcinoma espinocelular envolvendo a comissura anterior e tratados com MEL, envolvendo tanto tratamentos primários como resgates. Destes, 23 pacientes tinham câncer inicial (T1-2) e 16 tinham câncer em estádio mais avançado (T3-4). Nenhum dos pacientes com tumores iniciais (pT1 ou pT2a) teve recorrência local, sendo que nenhum recebeu RT pós-operatória. Cinco dos 22 pacientes com neoplasias intermediárias ou avançadas ( $\mathrm{pT2b} / \mathrm{T} 3$ ou T4) precisaram de um segundo tratamento devido à doença persistente ou recorrente. Segundo os autores, a MEL é uma ótima opção para a maioria dos pacientes com cânceres iniciais e intermediários envolvendo a comissura anterior $^{43}$.

Ainda em 2003, Martín Villares et al. realizaram um estudo histopatológico com 31 peças de laringectomia total ou parcial de pacientes tratados por carcinoma de laringe com acometimento de comissura anterior, em todos os estádios. Esses pacientes acabaram sendo divididos em dois grupos. No primeiro, chamado de tumores não infiltrativos de comissura anterior, a comissura estava afetada pelo câncer, mas sem invasão em profundidade. Nesse grupo, havia 18 pacientes, sendo que todos tinham 
mobilidade normal das pregas vocais e o câncer limitava-se ao plano glótico. No segundo grupo, com lesões agressivas que infiltravam a comissura anterior em profundidade, todos os pacientes apresentavam envolvimento de ambas as pregas vocais e alguma alteração de mobilidade destas. Nenhum destes pacientes tinha doença contida somente na glote. Dos 13 pacientes deste grupo, dez apresentavam invasão da cartilagem. Destes dez, nove apresentavam disseminação infraglótica do tumor. Além disso, dos dez pacientes com invasão de cartilagem, seis tumores extravasavam a laringe. A disseminação para fora da laringe foi caudal, até a infraglote, com invasão da membrana cricotireoide. Os autores concluíram que se, ao estudo endoscópico e estroboscópico, o câncer for estritamente glótico e com mobilidade normal das pregas vocais, o risco de invasão da cartilagem é mínimo ${ }^{44}$.

Em 2004, Zouhair et al. realizaram um estudo com 122 pacientes com carcinomas glóticos precoces tratados com RT, com o principal objetivo de verificar a importância do acometimento da comissura anterior como um fator prognóstico independente. Nas análises uni e multivariada, revelaram que o envolvimento da comissura anterior e a proteção das aritenoides na RT foram associados a pior prognóstico em termos de controle local. 
Sugerem que a RT não se constitui no melhor tratamento quando há presença de envolvimento da comissura anterior, devendo ser utilizados procedimentos cirúrgicos, radioquimioterapia e novas técnicas de RT nesses casos ${ }^{7}$.

Ainda em 2004, Steiner et al. descreveram um estudo retrospectivo envolvendo 263 pacientes submetidos à MEL devido a carcinomas glóticos precoces e encontraram 34 (13\%) pacientes com recorrência locorregional, sendo que 21 (62\%) tinham envolvimento da comissura anterior. As taxas de controle local em cinco anos para pacientes com e sem envolvimento de comissura anterior foi $84 \%$ contra $90 \%$ para câncer T1a, 73\% contra 92\% para lesão T1b e 79\% contra 74\% para câncer T2b, respectivamente. Vinte e dos 89 pacientes (24\%) com envolvimento de comissura anterior desenvolveram recorrência local. O local de recorrência incluiu a comissura anterior em 14 casos (16\%) e 13 dos 174 pacientes $(7 \%)$ sem envolvimento primário da comissura anterior desenvolveram recorrência local. Com isso, os autores afirmaram que a MEL é uma opção terapêutica efetiva em carcinoma glótico precoce com envolvimento da comissura anterior. As taxas de controle local foram similares àquelas obtidas pela radioterapia ou pelo procedimento aberto, mas sem as desvantagens desses outros procedimentos $^{14}$. 
Devido aos resultados conflitantes da MEL quando utilizada em neoplasias envolvendo a comissura anterior, foi desenvolvida a técnica da laringectomia parcial vertical endoscópica (EVPL). Nessa técnica, é realizada a ressecção das pregas vestibulares, permitindo melhor exposição superior da cartilagem tireoide. É feita a dissecção do pericôndrio interno dessa cartilagem, permitindo a interpretação microscópica da presença ou ausência de invasão desta cartilagem, permitindo a ressecção da porção anterior da mesma cartilagem na comissura anterior, quando necessário. Além de melhorar o estadiamento dos pacientes durante a operação, a EVPL resulta em excelente controle local, permitindo ressecções semelhantes às realizadas na laringectomia frontolateral aberta e com menor morbidade. Segundo Davis et al. em 2004, a EVPL, como tratamento único, controlou todos os casos de T1b e T2a glóticos. Assim, a EVPL teria vantagens no tratamento dos carcinomas glóticos com acometimento da comissura anterior, quando comparada às demais modalidades de tratamento ${ }^{45}$.

Em 2004, verificando que na literatura não havia dados comparando os métodos diagnósticos na avaliação da comissura anterior, dos ventrículos e da infraglote nos cânceres de laringe, Eryilmaz et al. realizaram um estudo comparativo entre a laringoscopia indireta, telescopia com $70^{\circ}$, tomografia 
computadorizada (TC) e microlaringoscopia de suspensão, comparando-as quanto ao envolvimento da comissura anterior, ventrículos e área infraglótica. A sensibilidade da laringoscopia indireta foi de $20-25 \%$, da laringoscopia direta foi de $50-70 \%$ e, para a TC e a telescopia, foi de 70-100\%. Na região infraglótica, a telescopia foi superior à TC. Os autores concluíram que a melhor maneira de avaliar a laringe quanto a invasão destas áreas é o uso combinado da TC e da telescopia ${ }^{46}$.

Em 2005, Nur et al., avaliando 114 pacientes com câncer T1T2 glóticos tratados com RT, obtiveram $84,2 \%$ de controle local em cinco anos ( $\mathrm{T} 1=88 \%$ e $\mathrm{T} 2=62 \%)$ em pacientes com acometimento de comissura anterior contra 95\% (T1=90\% e $\mathrm{T} 2=74 \%)$ em pacientes sem acometimento de comissura anterior. Apesar do acometimento de comissura anterior apresentar-se como fator de pior resposta ao tratamento à análise univariada, somente 0 estadiamento (T2) mostrou-se significante à análise multivariada. Assim, chegaram à conclusão de que o acometimento da comissura anterior não se constitui em fator de pior prognóstico para o tratamento com RT nesses casos. Nesse mesmo estudo, ao associar a radioterapia com operação de resgate, tiveram taxas de controle local em 5 anos de $96,9 \%{ }^{47}$. 
Barbosa et al. publicaram em 2005, um estudo comparando a laringoscopia e a TC quanto à eficácia no estadiamento de neoplasias que se estendiam até a comissura anterior. Quando comparada ao estadiamento patológico, a laringoscopia estava correta em $40,38 \%$ dos casos (40\% para $\mathrm{T} 1 ; 29,41 \%$ para $\mathrm{T} 2$; 26,43\% para T3; e 50\% para T4). A acurácia da TC foi de $75 \%$, sendo mais importante para T2 (62,50\%), T3 (73,91\%) e T4 (88,24\%). A identificação de sinais tomográficos de invasão de comissura anterior aumentou a acurácia da TC para 96\%. Concluiuse que a avaliação endoscópica subestadiou os tumores em todos os estádios, com exceção dos T1. A TC com cortes finos teve um importante papel no estadiamento correto em tumores mais avançados acometendo a comissura anterior ${ }^{48}$.

Ainda em 2005, Sewnaik et al. descreveram boas taxas de controle local em operações parciais para resgate pós-radioterapia. Oito de 18 pacientes com acometimento de comissura anterior conseguiram bons resultados utilizando MEL e 15 de 21 pacientes utilizando laringectomia frontolateral tiveram bons resultados. Com isso, chegaram à conclusão de que a operação parcial pode ter bom resultado quando bem indicada no resgate de pacientes após a $R T^{12}$. 
Em artigo de revisão de 2007, Herranz e Vázquez-Barros analisaram 25 artigos relacionados com câncer de laringe e a comissura anterior tratados com RT, MEL ou laringectomia parcial. A maior parte dos estudos mostrou piores taxas de sucesso quando o envolvimento da comissura anterior estava presente e somente dois estudos não encontraram diferença prognóstica ${ }^{49}$.

Em 2008, Celedón et al. publicaram uma avaliação no tratamento do câncer glótico. Os autores incluíram 96 pacientes com câncer laríngeo precoce de glote, 51 destes foram submetidos a laringectomia parcial e 45 recebeu RT. Houve recidiva em um paciente (2\%) submetido ao procedimento cirúrgico e em quatro dos tratados com RT (9\%). A taxa de sobrevida foi de $91 \%$ para a RT e $100 \%$ para a laringectomia parcial. Avaliando a comissura anterior, encontraram seu acometimento em 38 casos (75\%) submetidos à laringectomia frontolateral e 11 (25\%) pacientes que receberam RT. Todos os pacientes que apresentaram recidiva do câncer laríngeo tinham previamente comprometimento da comissura anterior, com maior recidiva presente no grupo tratado com $\mathrm{RT}(18 \%)$ em comparação ao grupo submetido à laringectomia parcial $(5 \%)^{50}$.

Já em 2009, Sachse et al. não encontraram diferença estatística nos pacientes com câncer glótico precoce que envolvia a comissura anterior comparando o tratamento com laringectomia 
parcial externa ou MEL. A taxa de recorrência local observada foi mais frequente se a comissura anterior estava acometida. $O$ controle local em 3 anos para câncer T1a foi de $82 \%$ com envolvimento de comissura anterior e de $93 \%$ naqueles sem envolvimento tratados com laringectomia parcial. No grupo tratado com MEL, a taxa de controle local com e sem acometimento da comissura anterior foi de 83 e $93 \%$, respectivamente ${ }^{51}$.

Em 2011, Tong et al. relataram um estudo retrospectivo de 433 pacientes com câncer laríngeo, todos em estádio T1, tratados com RT. A taxa de sobrevida em 5 anos foi de $92 \%$ no grupo T1a e 89\% no grupo T1b. Encontraram diferença estatística no prognóstico na presença de envolvimento da comissura anterior, grau de diferenciação histológica e dose de radiação utilizada. A taxa de controle local em 5 anos foi de $95 \%$ na ausência do acometimento da comissura anterior e de $86 \%$ quando envolvia a comissura anterior $(p=0,011)^{52}$.

Em 2012, Fouscher et al. revisaram 127 pacientes com câncer laríngeo tratados unicamente com cirurgia (laringectomia total ou parcial). Os autores compararam o estadiamento pré-operatório (endoscopia laríngea e TC) com a classificação pós-operatória (estadiamento patológico). Setenta e seis por cento dos tumores foram corretamente classificados no pré operatório e apenas $64 \%$ 
dos cânceres T3 e T4 foram corretamente classificados; $24,6 \%$ das neoplasias T2 e 33,3\% das neoplasias T3 foram reclassificados para T4 após a análise histopatológica. Os autores concluíram que a invasão do tecido cartilaginoso é frequentemente subestimado com a endoscopia laríngea e $\mathrm{TC}^{53}$.

Hartl et al. publicaram, em 2012, um estudo histopatológico de 94 espécimes de laringectomia parcial de carcinoma laríngeo precoce que acometessem a comissura anterior. A incidência geral de invasão da cartilagem tireoide foi de $8,5 \%$ (oito casos). Todos os casos de invasão atingiram somente o córtex interno e não houve nenhum caso que ultrapassasse a cartilagem (nenhuma lesão foi classificada com T4). Sete desses casos mudaram de lesões T2 para T3 e um caso foi classificado clinicamente como T3 pela fixação da prega vocal. A invasão da cartilagem teve relação significativa com a mobilidade das pregas vocais, com invasão de quatro dos 13 tumores (31\%) que tinham diminuição da mobilidade da prega vocal contra quatro dos 81 tumores (5\%) daqueles com mobilidade normal $(p=0,002)$. A invasão da cartilagem não teve relação com a extensão supraglótica ou infraglótica, acometimento unilateral, bilateral ou lesões isoladas de comissura anterior ou predição tomográfica $(p>0,05)$. Houve uma taxa de controle local de 
94\% das neoplasia sem invasão da cartilagem e 83\% daqueles com invação ${ }^{54}$.

Já em 2013, Szyfter et al. publicaram um estudo com a análise clínica e histopatológica de 108 pacientes tratados com laringectomia parcial aberta. A margem cirúrgica foi negativa em todos os casos. Em 29 casos, houve invasão subglótica e, em quatro pacientes, foi encontrada invasão da cartilagem tireoide. A taxa de sobrevida foi de $98,1 \%$ e $97,2 \%$ em 3 e 5 anos, respectivamente. Não houve menção de mudança do prognóstico em relação à invasão da cartilagem ${ }^{55}$.

Em 2013, Taylor et al. publicaram um estudo com 63 pacientes com câncer glótico com estádio T1b comparando 0 tratamento com RT à MEL. Não houve diferença estatística nas taxas de sobrevida a dois anos. Houve controle local de $95 \%$ dos casos submetidos à MEL contra $85,9 \%$ da RT e sobrevida geral de $94 \%$ em ambos os grupo ${ }^{56}$.

Em 2014, Mizrachi et al. analisaram o insucesso da MEL para o câncer glótico precoce. Encontraram taxas superiores de recorrência quando havia o acometimento da comissura anterior comparada a lesões limitadas ao terço médio da prega vocal ${ }^{57}$.

Ainda em 2014, Milovanovic et al. avaliaram 61 pacientes com câncer glótico in situ ou T1a e comparando a MEL e por meio de 
laringofissura. Doença recorrente ocorreu em 7,7\% dos pacientes tratados com MEL e $9,1 \%$ das operações abertas. Os autores demonstraram menor tempo de internação e menos necessidade de traqueostomia temporária no grupo tratado com $\mathrm{MEL}^{58}$.

Em 2015, Leszcznska et al. estudaram prospectivamente 254 pacientes com câncer laríngeo T2a (87 casos), T2b (77 casos) e T3 (90 casos) com envolvimento da comissura anterior. Todos os pacientes foram submetidos à laringectomia parcial. Na análise histopatológica, os autores encontraram 16 casos de metástase pré-laríngea, infiltração pericondrial em 11 pacientes, oito casos de invasão do tecido cartilaginoso, dois pacientes com invasão de microvasos e um com infiltração perineural. Dos 254 pacientes, 36 tiveram recorrência local; destes, nove tinham alterações histológicas adversas. As taxas de controle local e de sobrevida em 5 anos foram estatisticamente piores nos pacientes que apresentaram metástase pré-laríngea. Os autores não encontraram diferença estatística quando compararam as outras alterações histológicas adversas e pacientes sem elas ${ }^{59}$.

Ainda em 2015, Mendelson et al. relacionaram 30 pacientes com câncer de andar glótico (T1 e T2) tratados com MEL. Os autores descreveram uma taxa de recorrência local de 16.7\% (5 casos); destes, dois foram submetidos a nova MEL e dois foram 
submetidos à laringectomia total. A taxa de preservação da laringe foi de $93.3 \%$ (28 casos) e sobrevida geral de $96.7 \%{ }^{60}$.

Em 2015, Wu et al. publicaram um estudo com 31 pacientes com câncer de glote. Esses pacientes foram analisados com endoscopia e TC pré-operatória e submetidos à ressecção cirúrgica (laringectomia total ou parcial). Ocorreu extensão supraglótica em 27 pacientes $(87,1 \%)$ e, em quatro deles, a comissura anterior foi acometida (14,8\%). A extensão infraglótica ocorreu mais frequentemente pela área da comissura anterior $(71,4 \%)$. Oito casos apresentaram envolvimento da lâmina intermediária da cartilagem tireoidea (25,9\%). Dezoito pacientes exibiram neoplasias que invadiam somente a face dorsal do ligamento de Broyles e não atingiram a cartilagem. Os autores concluíram que o ligamento de Broyles teria agido como uma barreira contra a invasão tumoral ${ }^{61}$.

Em 2016, Ulusan et al. descreveram a incidência da invasão da cartilagem tireoidea em 62 pacientes com cânceres precoces de laringe que envolviam a comissura anterior e que foram submetidos à laringectomia parcial. Os pacientes foram divididos em dois grupos de acordo com a analise macroscópica: grupo 1 (37 pacientes) se o câncer estava limitado à glote com envolvimento da comissura anterior; e grupo 2 (25 pacientes) para cânceres que invadiam a supraglote e glote com envolvimento da comissura 
anterior. A invasão da cartilagem tireoide foi observada em 10 pacientes $(16,1 \%)$, com invasão macroscópica em dois deles e microscópica em oito. Apenas dois desses pacientes eram do grupo 1 (taxa de invasão da cartilagem de 5,4\%) e os oito restantes eram do grupo 2 (taxa de invasão da cartilagem de 32\%). Assim, houve uma probabilidade estatisticamente maior de invasão da cartilagem tireoide nos tumores com extensão supraglótica comparados aos tumores glóticos isolados $(p=0.011)^{62}$.

No mesmo ano, Kitani et al. publicaram estudo retrospectivo analisando fatores prognósticos no tratamento radioterápico do câncer glótico T1 e T2. Foram analisados 130 pacientes consecutivos, sendo 63 pacientes com câncer T1 e 67 com câncer T2. A taxa de controle local em 5 anos de todos os pacientes foi de 81\%. Já o controle local nos pacientes com câncer T1 e T2 foi de $89 \%$ e $74 \%$, respectivamente. A análise multivariada identificou que apenas o envolvimento da comissura anterior foi fator prognóstico estatisticamente relevante no controle neoplásico local (91\% vs. $51 \%)^{63}$ 
4 MÉTODOS 


\section{MÉTODOS}

Após aprovação pelo parecer 338/13 do Instituto do Câncer do Estado de São Paulo, esta pesquisa foi aprovada pelo Comitê de Ética em Pesquisa do Hospital das Clínicas da Faculdade de Medicina da Universidade de São Paulo sob o parecer número 426.662, de 16/10/2013 - Anexos 1 e 2.

\subsection{Casuística}

Foram incluídos neste estudo 48 pacientes submetidos à laringectomia frontolateral nos Serviços de Cirurgia de Cabeça e Pescoço do Hospital das Clínicas da Faculdade de Medicina da Universidade de São Paulo, do Instituto do Câncer do Estado de São Paulo e do Hospital Ana Costa, Santos.

Como critérios de inclusão, foram considerados todos os pacientes submetidos à laringectomia parcial frontolateral por carcinoma espinocelular precoce (T1b ou T2, na classificação TNM) de glote e que atingissem a comissura anterior.

Consideraram-se como critério de exclusão blocos de parafina/lâminas em que não pode haver análise precisa da cartilagem tireoide no nível da comissura anterior. 
A mediana de idade foi de 61 anos, com variação entre 40 e 77 anos. A maioria dos pacientes era do sexo masculino $(89,6 \%)$. Dos pacientes, $44(91,6 \%)$ eram tabagistas e 12 (25\%) eram etilistas. A mediana do início dos sintomas até o diagnóstico foi de 3 meses, variando de 1 a 24 meses.

\subsection{Análise histopatológica}

Foram avaliadas as lâminas histopatológicas dos espécimes cirúrgicos dos pacientes submetidos à laringectomia frontolateral por carcinoma de células escamosas precoce de laringe, estadiados clinicamente como $\mathrm{T} 1 \mathrm{~b}$ ou $\mathrm{T} 2$, de acordo com as diretrizes da American Joint Committee on Cancer, $2010^{64}$.

\subsubsection{Macroscopia}

Como rotina, um dos cirurgiões participou da preparação e avaliação macroscópicas dos espécimes cirúrgicos. Os espécimes para a microscopia óptica, logo após a obtenção, foram imersos por cerca de três horas em solução de formol a 10\%. Em seguida, foram dissecados com lâmina de aço, separando-se um fragmento representativo da interface do tumor com a comissura anterior e obedecendo a um corte axial - Figura 1. Foram realizados cortes 
axiais seriados na altura da implantação das pregas vocais na comissura anterior, para que se pudesse avaliá-la.

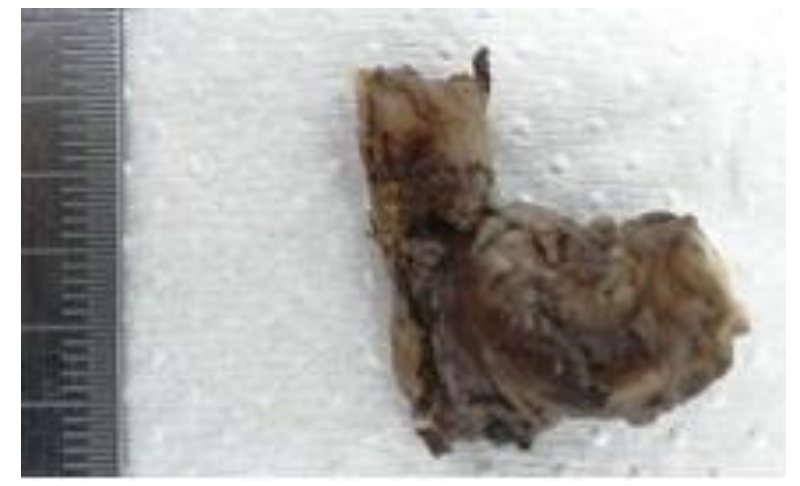

Figura 1 - Aspecto macroscópico de um espécime.

\subsubsection{Microscopia}

O preparo e estudo histopatológicos foram realizados nos respectivos laboratórios de Anatomia Patológica. Os fragmentos foram fixados em formol a 10\%. A descalcificação foi obtida colocando-se o espécime em solução de ácido nítrico, por um período que variou de um a três dias. A etapa seguinte compreendeu a desidratação dos espécimes e, para tanto, utilizouse álcool etílico em concentrações progressivamente maiores, até o absoluto. Convenientemente desidratadas em álcool absoluto, as peças foram depois diafanizadas pelo xilol e impregnadas pela parafina líquida em estufa regulada à temperatura de $59^{\circ} \mathrm{C}$, segundo a metodologia preconizada por Masson ${ }^{65}$ e, posteriormente, impregnadas na parafina fundida a $60^{\circ}$. Em 
seguida, os blocos foram cortados em micrótomo tipo Minot®, ajustado para $5 \mu \mathrm{m}$ de espessura. Na parafina, as peças foram incluídas e orientadas de tal maneira que, nos cortes histológicos, pudessem ser apreciados o tumor e suas relações com as estruturas circunjacentes. Os cortes obtidos foram colados em lâminas previamente untadas com albumina de Mayer; as lâminas foram mantidas em uma estufa regulada à temperatura de $37^{\circ} \mathrm{C}$, durante 24 horas, para secagem e colagem dos cortes. Foram realizadas as colorações por hematoxilina-eosina $(\mathrm{HE})^{66}$.

As lâminas foram pesquisadas nos respectivos serviços de Anatomia Patológica dos hospitais participantes do estudo. Foram utilizadas as lâminas dos cortes axiais realizados na altura da implantação das pregas vocais. Caso não tenham sido realizados cortes no plano axial, foram utilizadas lâminas de cortes sagitais medianos.

Foram analisados os blocos de parafina dos quais se originaram as lâminas selecionadas. Caso a avaliação das lâminas inicialmente disponíveis não tivesse sido conclusiva, foram feitos novos cortes seriados nesses blocos com o uso de micrótomo e, com isso, foram feitas novas lâminas. Em cada lâmina, foi avaliada a presença de invasão de tecido cartilaginoso por parte do tumor, a extensão e a profundidade da invasão. 
Todas as lâminas foram reavaliadas por um mesmo patologista da Clínica Diagnos, de Santos (Dr. Ricardo Camillo de Almeida). Todos os espécimes de microscopia óptica forma avaliados com o auxílio de um microscópio de luz modelo Zeiss®, com aumento de 140, 240 e 280 vezes.

Quanto ao envolvimento da cartilagem tireoide, os casos foram separados em três grupos: status 1, quando entre a neoplasia e a cartilagem houvesse a presença de tecido conjuntivo preservado; status 2, quando a neoplasia estava adjacente, porém sem acometer a cartilagem; status 3, quando a cartilagem estava infiltrada por tumor.

Na reavaliação dos espécimes, foram estudados os seguintes aspectos morfológicos: grau histológico, anaplasia, necrose tumoral, índice mitótico e distribuição de elastina, esta última somente nos casos em que houve o achado de tecido sadio entre o tumor e a cartilagem, com a finalidade de detectar-se alteração no arranjo por conta de infiltração tumoral na detectada pela coloração habitual.

O grau histológico foi estratificado em: grau I - carcinoma bem diferenciado; grau II - moderadamente diferenciado; e grau III pouco diferenciado.

Anaplasia pode ser usada como sinônimo para indiferenciação de células tumorais. Nesse sentido, foi 
desmembrada em irregularidade nuclear e nucleolos evidentes. Tanto as células quanto seus núcleos apresentam pleomorfismo variação em forma e volume. Podem ser encontradas células gigantes, maiores que as células vizinhas, enquanto outras células podem ser pequenas e com aspecto primitivo. Caracteristicamente, os núcleos contêm ácido desoxirribonucleico (ADN) em abundância e coram-se fortemente (hipercromasia). Os núcleos são desproporcionalmente grandes para as células e a relação núcleoplasmática pode aproximar-se de 1:1, ao invés da relação núcleoplasmática normal de 1:4 ou 1:6. A forma do núcleo é variável e a cromatina é grosseiramente granulosa e distribuída ao longo da membrana nuclear. Grandes nucléolos estão presentes nesses núcleos, refletindo a atividade de síntese dessas células. Tumores anaplásicos geralmente apresentam grande número de mitoses, refletindo a atividade proliferativa das células do tecido ${ }^{67}$. Assim, foi usado, para o núcleo, o grau de Furhman: 1 - normal; 2 - discreto; 3 - moderado; e 4 - intenso. Já a presença de nucléolo foi classificada em presente ou ausente ${ }^{67}$.

Necrose tumoral foi estudada na coloração de HE e dividida em presente e ausente. Morfologicamente, as células necróticas apresentam um aumento da eosinofilia, devido à perda da basofilia causada pelo ácido ribonucléico (ARN) no citoplasma normal e 
devido também ao aumento da ligação da eosina às proteínas plasmáticas desnaturadas. O citoplasma apresenta vacúolos e o citoplasma com um aspecto corroído, podendo haver calcificações. As células mortas podem ser substituídas por grandes massas de fosfolipídeos, denominadas figuras de mielina, que serão posteriormente fagocitadas por outras células ou degradadas em ácidos graxos ${ }^{68}$.

Quanto ao índice mitótico, é a percentagem de células que sofrem mitose na amostra. É diferente da contagem de mitoses. Trata-se da quantidade total de células são contados por adição do número de células mitóticas e as células não se dividem em conjunto. Deve-se dividir o número de células mitóticas pelo número total de células contadas. É a percentagem de células que sofrem mitose na amostra.

Para a pesquisa de elastina, foi realizada a coloração de Verhoeff. Os espécimes conservados em parafinas foram seccionados com cortes de $6 \mu \mathrm{m}$. Foi feita a desparafinização e hidratação com água destilada. Em seguida, prepara-se a solução de Verhoeff (lodo $2 \mathrm{~g}$, iodeto de potássio $4 \mathrm{~g}$ e $100 \mathrm{~mL}$ de água destilada): Os cristais de lodo e iodeto são misturados vigorosamente, adicionando-se gradualmente água destilada, $20 \mathrm{~mL}$ por vez. Em outro frasco, misturam-se solução de hematoxilina 
alcoólica a $10 \% 25 \mathrm{~mL}$, álcool etílico absoluto $25 \mathrm{~mL}$ e solução de cloridreto férrico a $10 \% 25 \mathrm{~mL}$ e, em seguida, agrega-se a solução de iodeto de Verhoeff, $25 \mathrm{~mL}$. Submete-se, por 15 minutos, o espécime a tal solução e lava-se com água corrente morna por 20 minutos, colocando-se em água destilada. Coloca-se em solução de desdiferenciação de cloridreto férrico a $2 \%$, checando-se microscopicamente as fibras de elastina coradas em preto agudamente finas, com pano de fundo cinza. A seguir, coloca-se em solução de tiossulfato de sódio a 5\% por um minuto, lavando-se com água por cinco minutos e colocando-se em água destilada. Depois, submete-se à solução de van Gieson por um minuto e desidrata-se rapidamente em álcool etílico a 95\% (duas trocas) e álcool absoluto (duas trocas). Finalmente, monta-se em meio de resina. Fibras elásticas e núcleos coram-se em preto, colágeno em vermelho e outras estruturas teciduais em amarelo ${ }^{69}$. Foi estratifica em mantida, ou seja, presente; ou perda, ou seja, estava ausente ou diminuída em relação ao normal.

\subsubsection{Aspectos epidemiológicos e clínicos}

Os prontuários dos pacientes foram analisados quanto a gênero, idade, tabagismo, etilismo, tempo de história prévia ao diagnóstico, exame de laringoscopia anterior à cirurgia, tratamentos 
prévios e adjuvantes, invasão de cartilagem ao exame macroscópico, presença de recidiva e tempo de seguimento.

Com esses dados, somados ao resultado da análise das lâminas foi preenchido o protocolo de pesquisa (Anexo 3).

\subsection{Análise estatística}

A distribuição de frequências foi utilizada para descrever as variáveis categóricas e as medidas de tendência central e de variabilidade para as numéricas ou continuas. Para comparar as medidas das variáveis numéricas (idade, tempo de historia e índice mitótico) em relação à variável condição da comissura anterior com duas categorias, o teste $U$ de Mann-Whitney foi aplicado e, no caso onde a variável tempo de seguimento mostrou normalidade dos dados, o teste $\mathrm{t}$ de Student foi adotado. Para verificar as associações entre variáveis categóricas e condição da comissura anterior com duas categorias, o teste de frequências do quiquadrado foi aplicado. O nível de significância de $5 \%$ foi considerado em todos os testes estatísticos. O programa estatístico para computadores STATA versão 10.0 foi utilizado para a realização das análises estatísticas (STATACorp. 2007. Stata Statistical Software: Release 10.0. College Station, Texas : Stata Corporation). 
5 RESULTADOS 


\section{RESULTADOS}

As Tabelas 1 e 2 descrevem a casuística de acordo com variáveis demográficas e patológicas.

A Tabela 1 descreve as características demográficas e macroscópicas dos pacientes avaliados. A mediana etária foi de 61 anos, com variação entre 40 e 77 anos. Houve predomínio do gênero masculino $(89,6 \%)$ e de tabagistas $(91,7 \%)$. A maioria dos pacientes não era etilista (75\%). Os pacientes apresentaram uma mediana de 3 meses de tempo de historia clinica até o diagnóstico da lesão, variação de 1 a 24 meses. O acometimento isolado de uma prega vocal ocorreu em $20(41,7 \%)$ casos e em 28 (58,3\%) atingiu ambas as pregas. O estádio T foi de T1b em 42 (87,5\%) e T2 em 6 (12,5\%) dos casos. Dos 48 espécimes histopatológicos analisados, houve a presença de tecido conjuntivo preservado entre a neoplasia e a cartilagem em 34 (70,8\%) pacientes (status 1); a neoplasia estava adjacente, porém, sem acometer a cartilagem em $10(20,8 \%)$ casos (status 2$)$; e a cartilagem estava infiltrada por tumor em $4(8,3 \%)$ casos (status 3$)$. 
Tabela 1 - Distribuição da casuística de acordo com variáveis demográficas e clínicas dos 48 pacientes.

\begin{tabular}{|c|c|c|}
\hline Variável & Categoria / Medidas & $\begin{array}{c}\text { Freq. (\%) / } \\
\text { Medidas }\end{array}$ \\
\hline Gênero & $\begin{array}{l}\text { Feminino } \\
\text { Masculino }\end{array}$ & $\begin{array}{c}5(10,4) \\
43(89,6) \\
\end{array}$ \\
\hline Idade (anos) & $\begin{array}{l}\text { Variação } \\
\text { Mediana } \\
\text { Média (Desvio-padrão) }\end{array}$ & $\begin{array}{c}40-77 \\
\quad 61 \\
61,2(8,1)\end{array}$ \\
\hline Tabagismo & $\begin{array}{l}\text { Não } \\
\text { Sim }\end{array}$ & $\begin{array}{c}4(8,3) \\
44(91,7) \\
\end{array}$ \\
\hline Etilismo & $\begin{array}{l}\text { Não } \\
\text { Sim }\end{array}$ & $\begin{array}{l}36(75,0) \\
12(25,0) \\
\end{array}$ \\
\hline Tempo de história (meses) & $\begin{array}{l}\text { Variação } \\
\text { Mediana } \\
\text { Média (Desvio-padrão) }\end{array}$ & $\begin{array}{c}1-24 \\
3 \\
4,6(3,7) \\
\end{array}$ \\
\hline Característica da lesão & $\begin{array}{l}\text { Unilateral } \\
\text { Bilateral }\end{array}$ & $\begin{array}{l}20(41,7) \\
28(58,3)\end{array}$ \\
\hline Estádio do tumor primário & $\begin{array}{l}\text { T1b } \\
\text { T2 }\end{array}$ & $\begin{array}{c}42(87,5) \\
6(12,5) \\
\end{array}$ \\
\hline Radioterapia adjuvante & $\begin{array}{l}\text { Não } \\
\text { Sim }\end{array}$ & $\begin{array}{c}43(89,6) \\
5(10,4)\end{array}$ \\
\hline Status da comissura anterior & $\begin{array}{l}1 \\
2 \\
3\end{array}$ & $\begin{array}{c}34(70,8) \\
10(20,8) \\
4(8,3) \\
\end{array}$ \\
\hline $\begin{array}{l}\text { Tempo de seguimento } \\
\text { (meses) }\end{array}$ & $\begin{array}{l}\text { Variação } \\
\text { Mediana } \\
\text { Média (Desvio-padrão) }\end{array}$ & $\begin{array}{c}18-60 \\
41 \\
41,1(13,0) \\
\end{array}$ \\
\hline Condição do paciente & $\begin{array}{l}2^{a} \text { lesão resgatada } \\
\text { Óbito pelo câncer } \\
\text { Vivo sem evidência de doença } \\
\text { Recidiva local resgatada LT + ECB }\end{array}$ & $\begin{aligned} 1 & (2,1) \\
2 & (4,2) \\
44 & (91,7) \\
1 & (2,1)\end{aligned}$ \\
\hline
\end{tabular}


A Tabela 2 informa a distribuição das variáveis patológicas. Quanto ao grau de diferenciação histológica, 12 (25\%) foram de tumores bem diferenciados, $33 \quad(68,8 \%)$ moderadamente diferenciados e $3(6,25 \%)$ deles eram pouco diferenciados. O índice mitótico apresentou mediana de 7, com uma variação de 1 a 37. Irregularidade nuclear foi intensa em 21 (43,8\%) das peças analisadas e moderada em 27 (56,2\%). Nucléolo estava presente em $31(64,6 \%)$ dos casos. Foi identificada necrose tumoral em apenas $1(2,1 \%)$ caso e necrose superficial em 2 (4,2\%) peças.

Tabela 2. Distribuição da casuística de acordo com variáveis patológicas dos 48 pacientes.

\begin{tabular}{llc} 
Variável & Categoria / Medidas & Freq. $(\%) /$ Medidas \\
\hline \multirow{2}{*}{ Grau histológico } & & $12(25,0)$ \\
& II & $33(68,8)$ \\
& Variação & $3(6,2)$ \\
\hline \multirow{2}{*}{ Índice mitótico } & Mediana & $1-37$ \\
& Média (Desvio-padrão) & 7 \\
& & $9,2(7,9)$ \\
\hline \multirow{2}{*}{ Irregularidade nuclear } & Intensa & $21(43,8)$ \\
& Moderada & $27(56,2)$ \\
\hline \multirow{2}{*}{ Nucléolo evidente } & Ausente & \\
& Presente & $31(64,6)$ \\
& Ausente & $17(35,4)$ \\
\hline \multirow{2}{*}{ Necrose tumoral } & Presente & $47(97,9)$ \\
& & $1(2,1)$ \\
\hline \multirow{2}{*}{ Necrose superficial } & Ausente & $46(95,8)$ \\
& Presente & $2(4,2)$ \\
& & \\
\hline
\end{tabular}


Os pacientes foram acompanhados por um período de 18 a 60 meses, mediana de 41 meses. Cinco (10,4\%) pacientes realizaram RT adjuvante por apresentarem margem cirúrgica focalmente comprometida. Dos 48 pacientes acompanhados, quatro $(8,3 \%)$ pacientes apresentaram desfecho desfavorável. Houve recidiva da neoplasia em três $(6,2 \%)$ pacientes, sendo que dois destes foram submetidos à laringectomia total de resgate. Houve o aparecimento de nova neoplasia primária na laringe em um paciente. Foram a óbito dois $(4,2 \%)$ pacientes pelo câncer de laringe e um caso foi a óbito por outra causa (infarto agudo do miocárdio).

Dos 34 casos em que a elastina foi investigada (aqueles com presença de tecido sadio entre o tumor e a cartilagem), em dois foi notada a presença de elastina (Figura 11), que esteve ausente em todos os demais (Figura 12). 


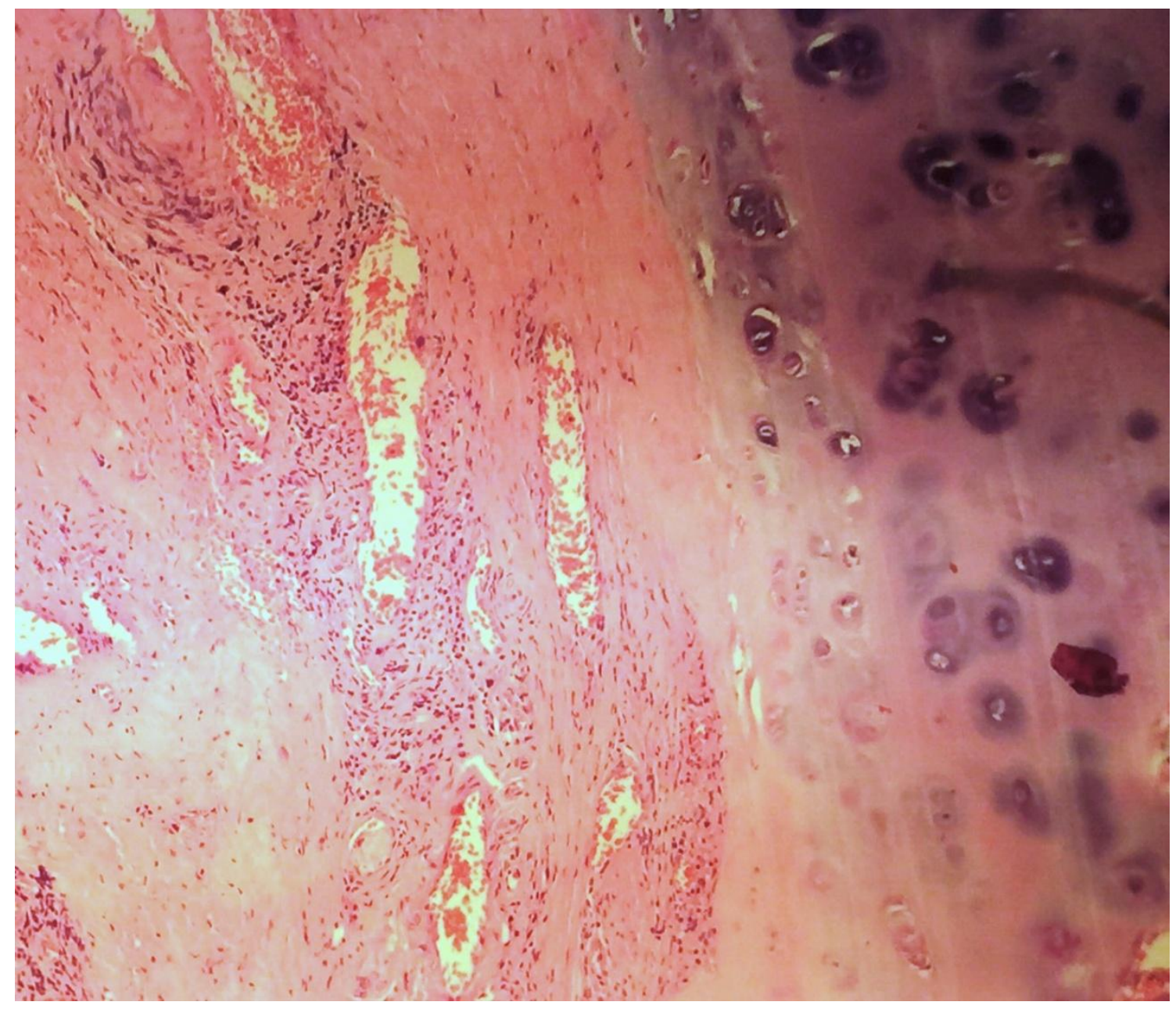

Figura 2 - Transição normal. HE objetiva de 10x. À direita tecido cartilaginoso maduro dentro dos limites da normalidade. Ao centro e esquerda tecido de granulação caracterizado por evidente proliferação capilar e processo inflamatório perivascular, compatível com tecido reparativo. Ausência de sinais de malignidade. 


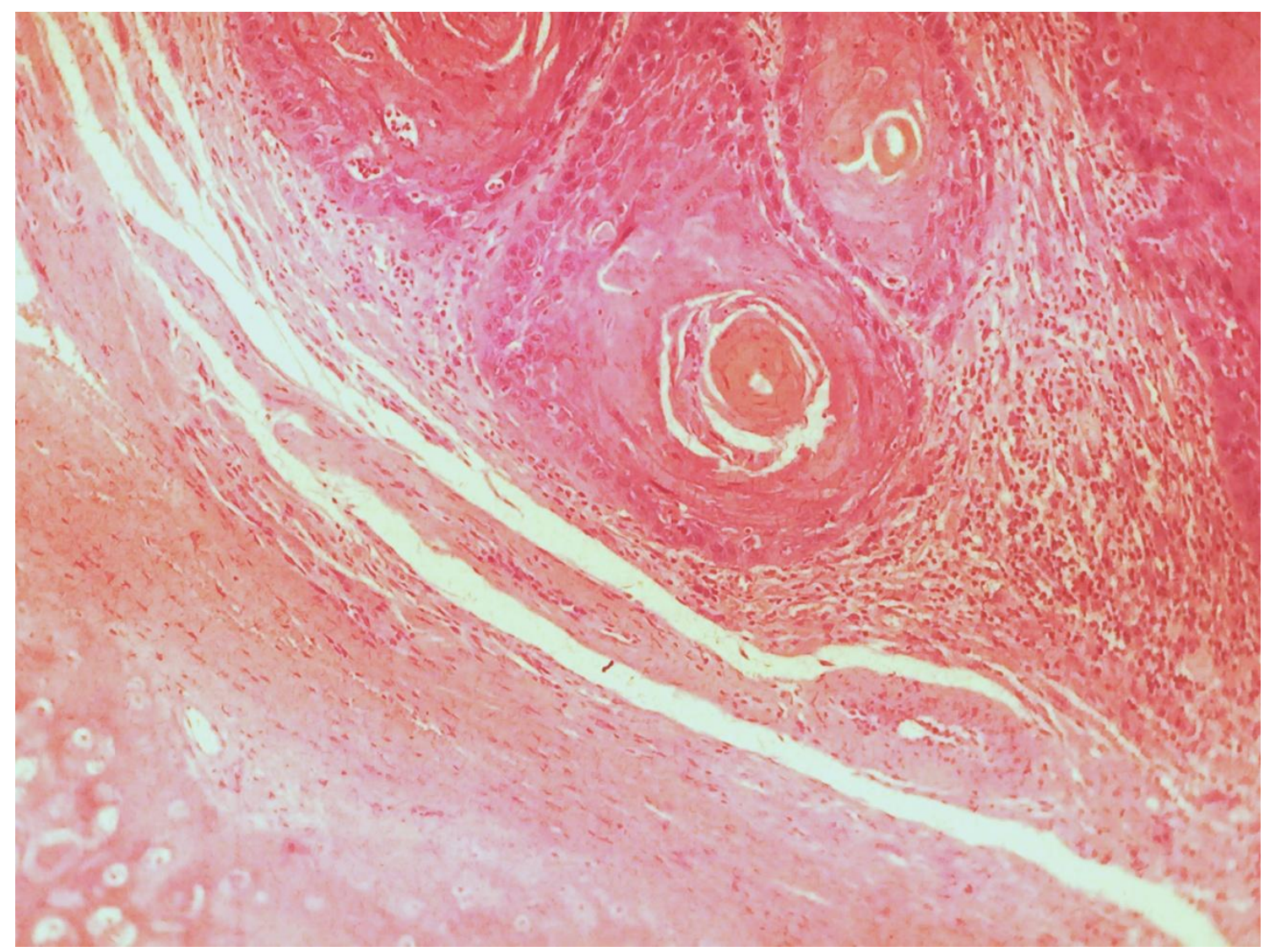

Figura 3 - Tumor adjacente à cartilagem. HE objetiva de 10x Cartilagem na porção inferior e carcinoma de células escamosas bem diferenciado, por mimetizar todos os elementos da pele normal, inclusive com formação de pérolas córneas, presente no campo superior junto ao pericôndrio da cartilagem tireoide, porém, sem invasão. 


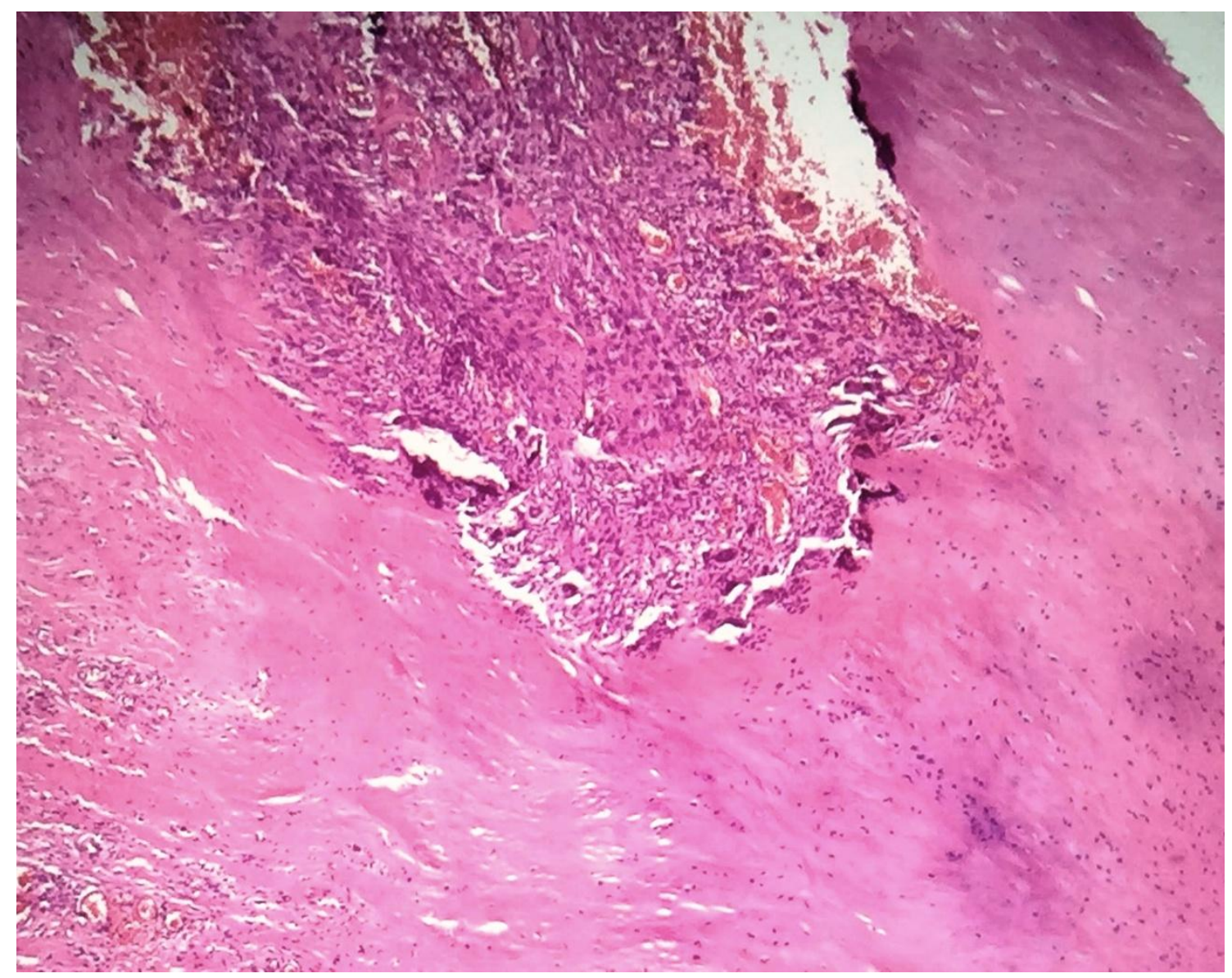

Figura 3 - Invasão pericondrial da cartilagem tireoide. HE objetiva de 10x - Evidente padrão de "roedura por traça" (irregularidade cartilaginosa) promovido no tecido cartilaginoso pela neoplasia. 


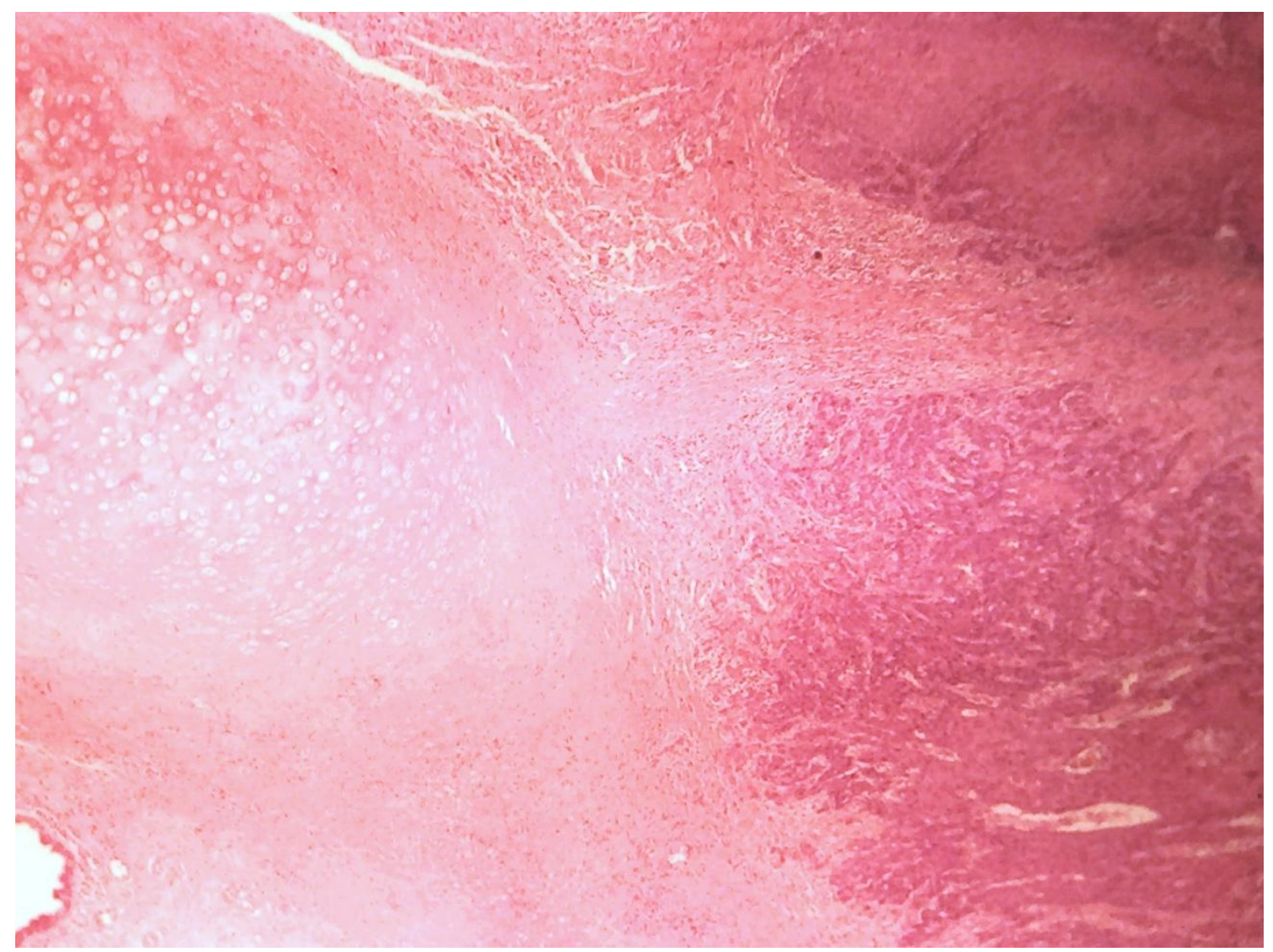

Figura 5 - Invasão pericondrial da cartilagem tireoide. HE objetiva de 10x - Presença de dois padrões de crescimento. Em blocos organóides (acima à direita) e espucilado (abaixo à direita). 


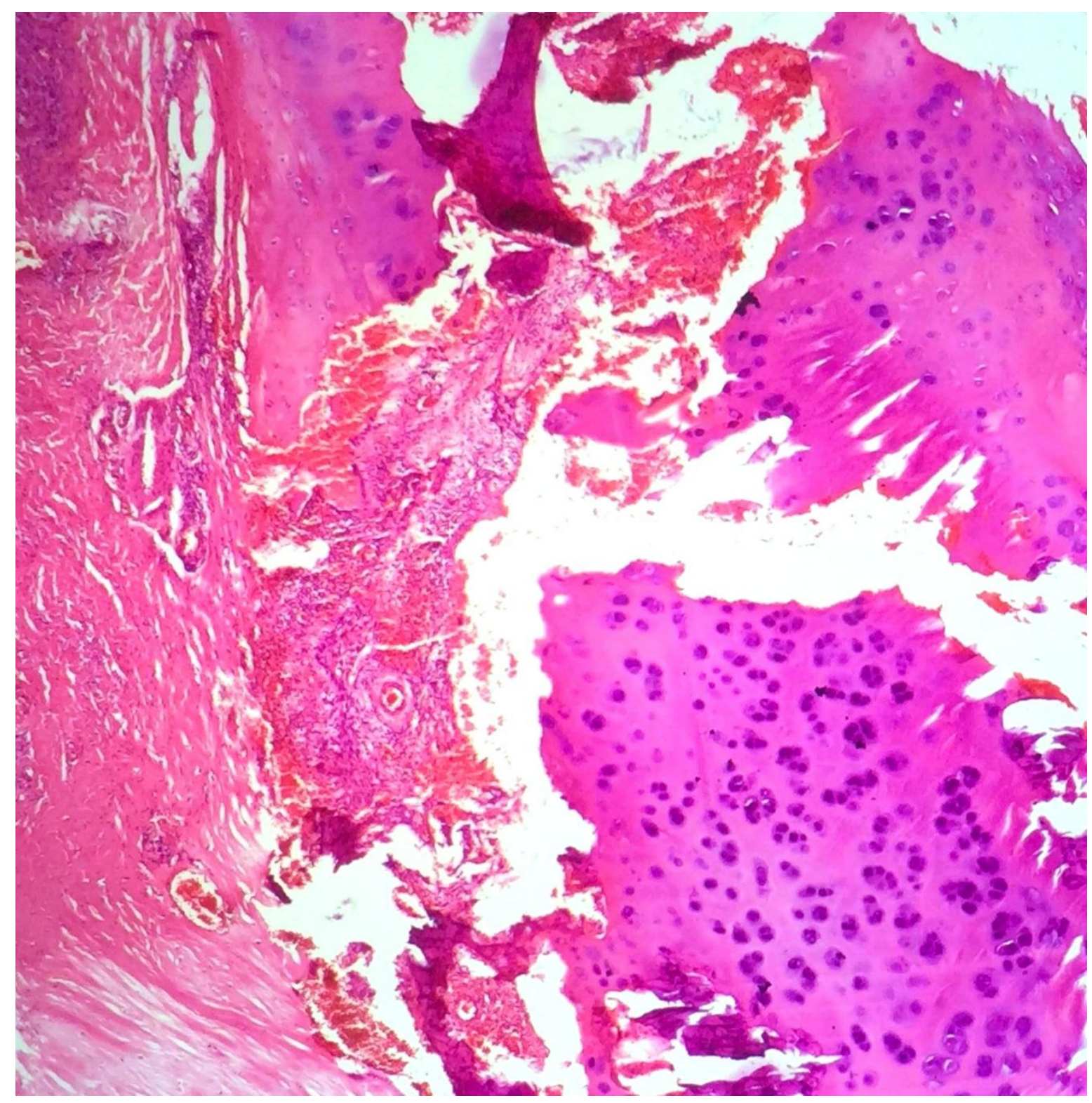

Figura 6 - Invasão da cartilagem tireoide na região central com fragmentação do tecido. HE, 40x. 


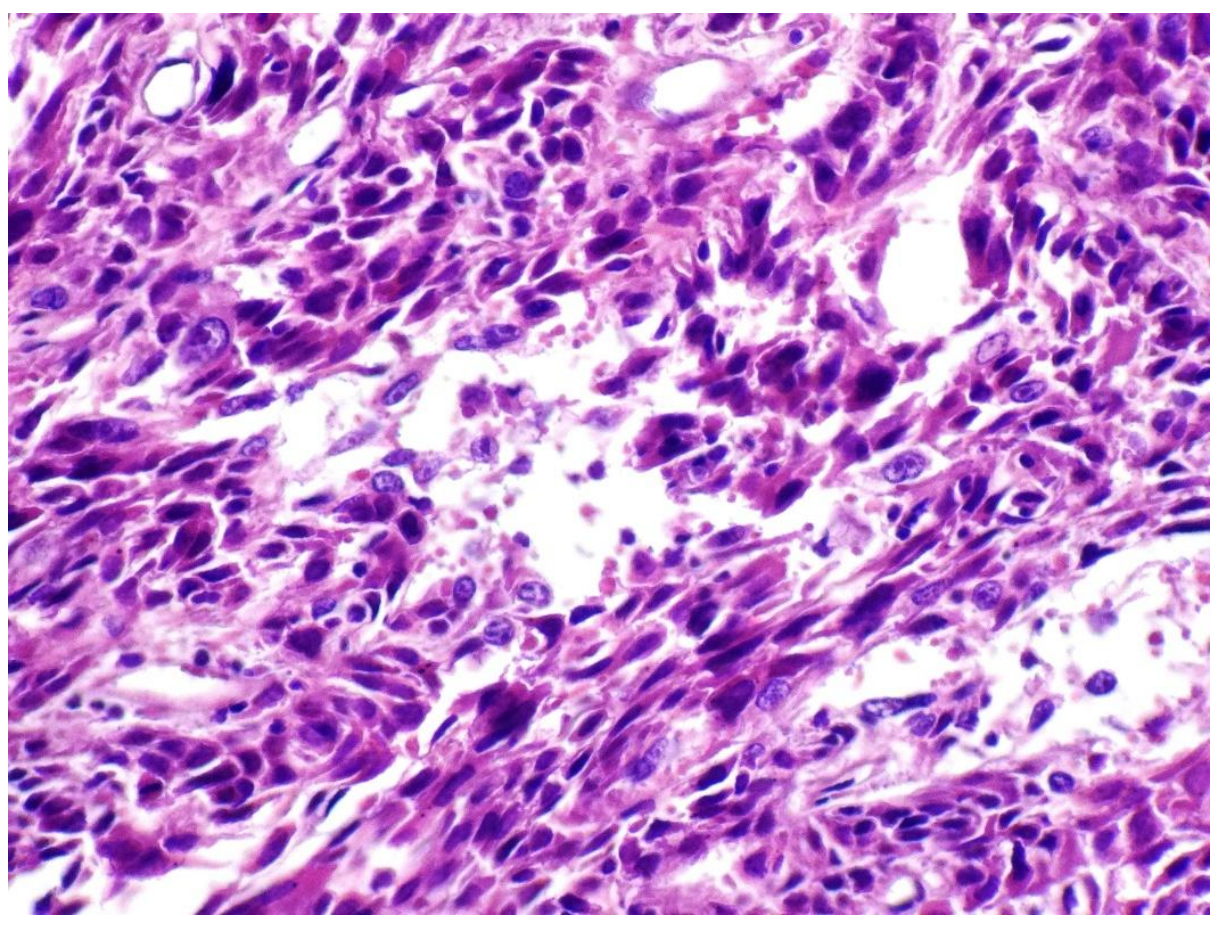

Figura 7 - Presença de irregularidade moderada, sem evidência de nucléolos. HE, 100x.

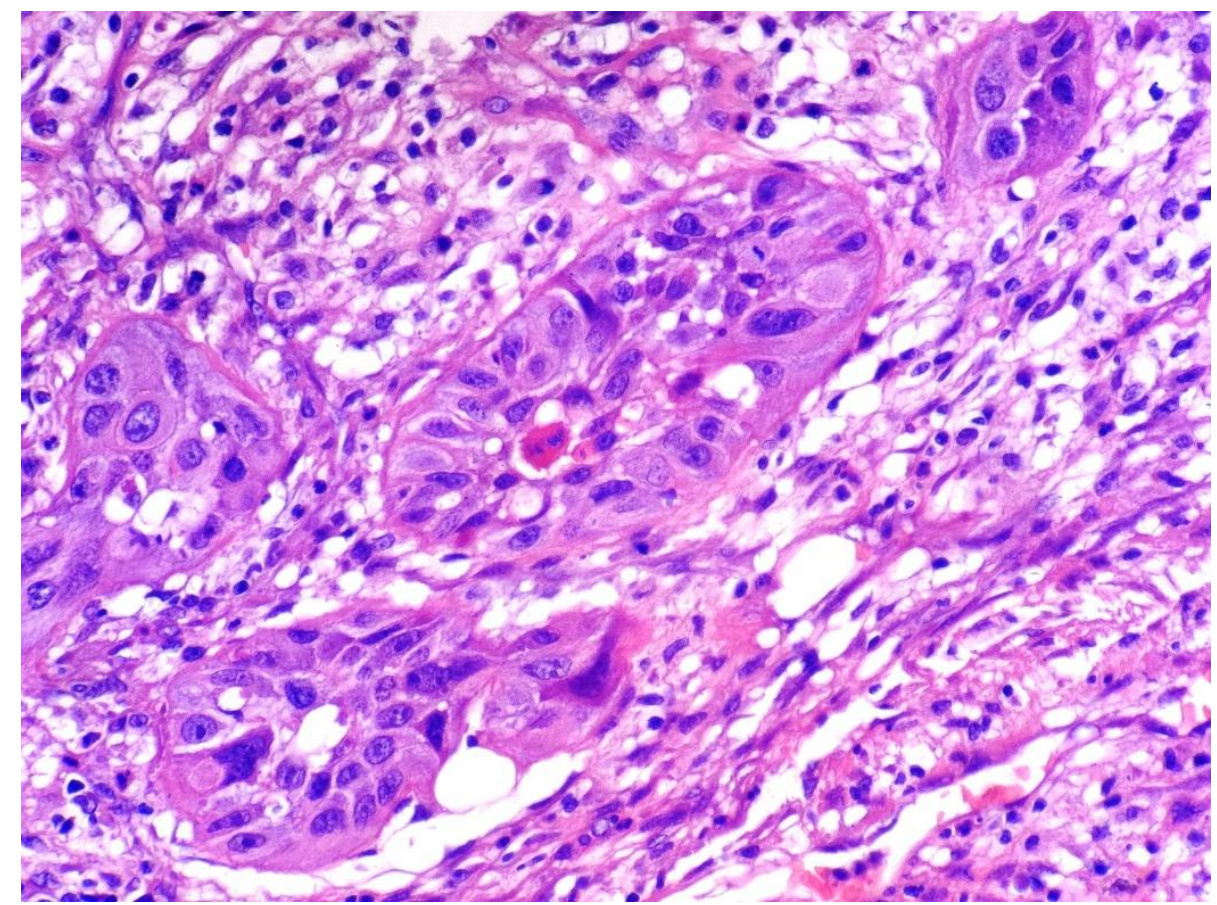

Figura 8 - Presença de irregularidade intensa e evidência de nucléolos. HE, 100x. 


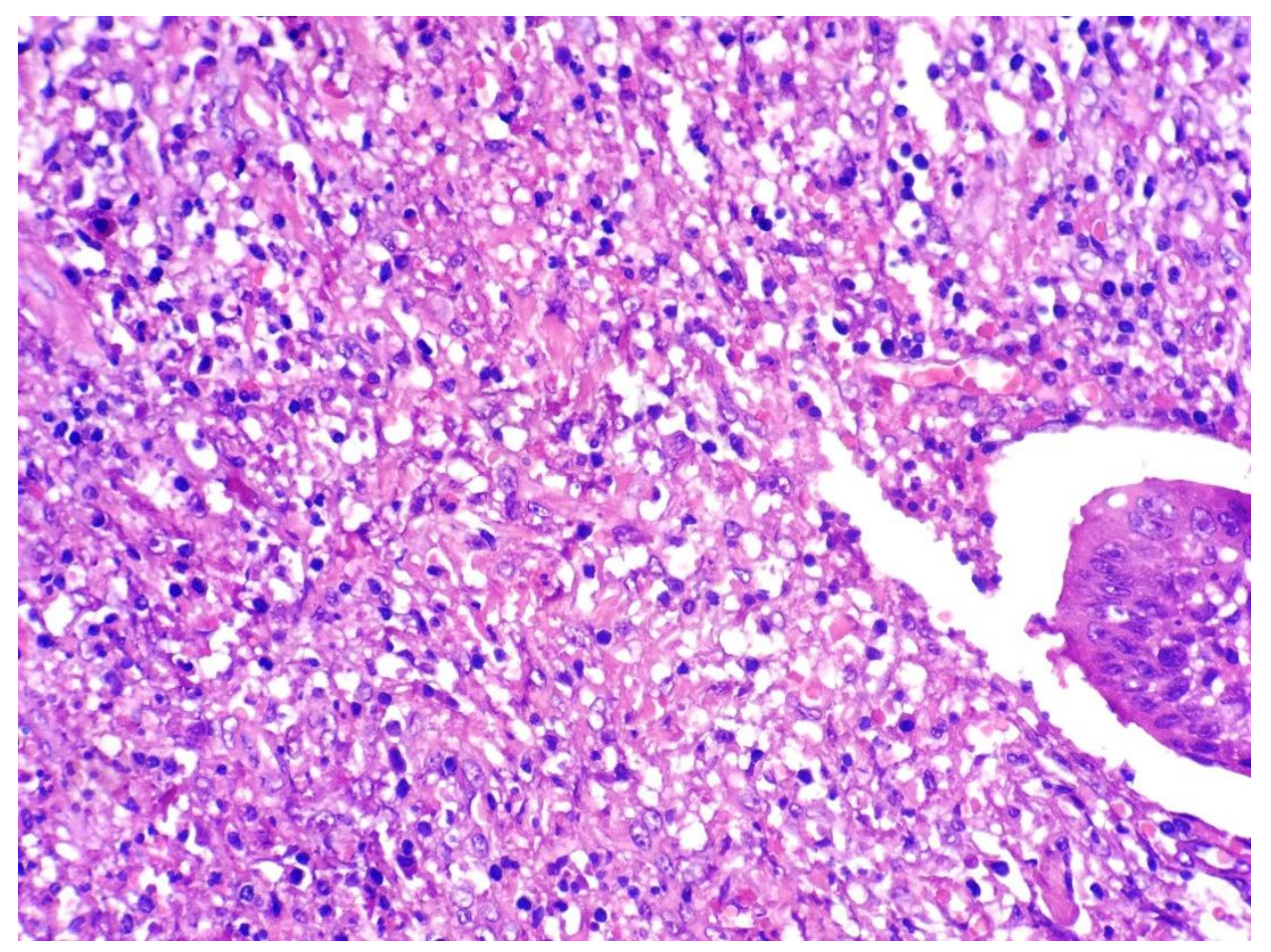

Figura 9 - Presença de necrose tumoral. HE, 100x.

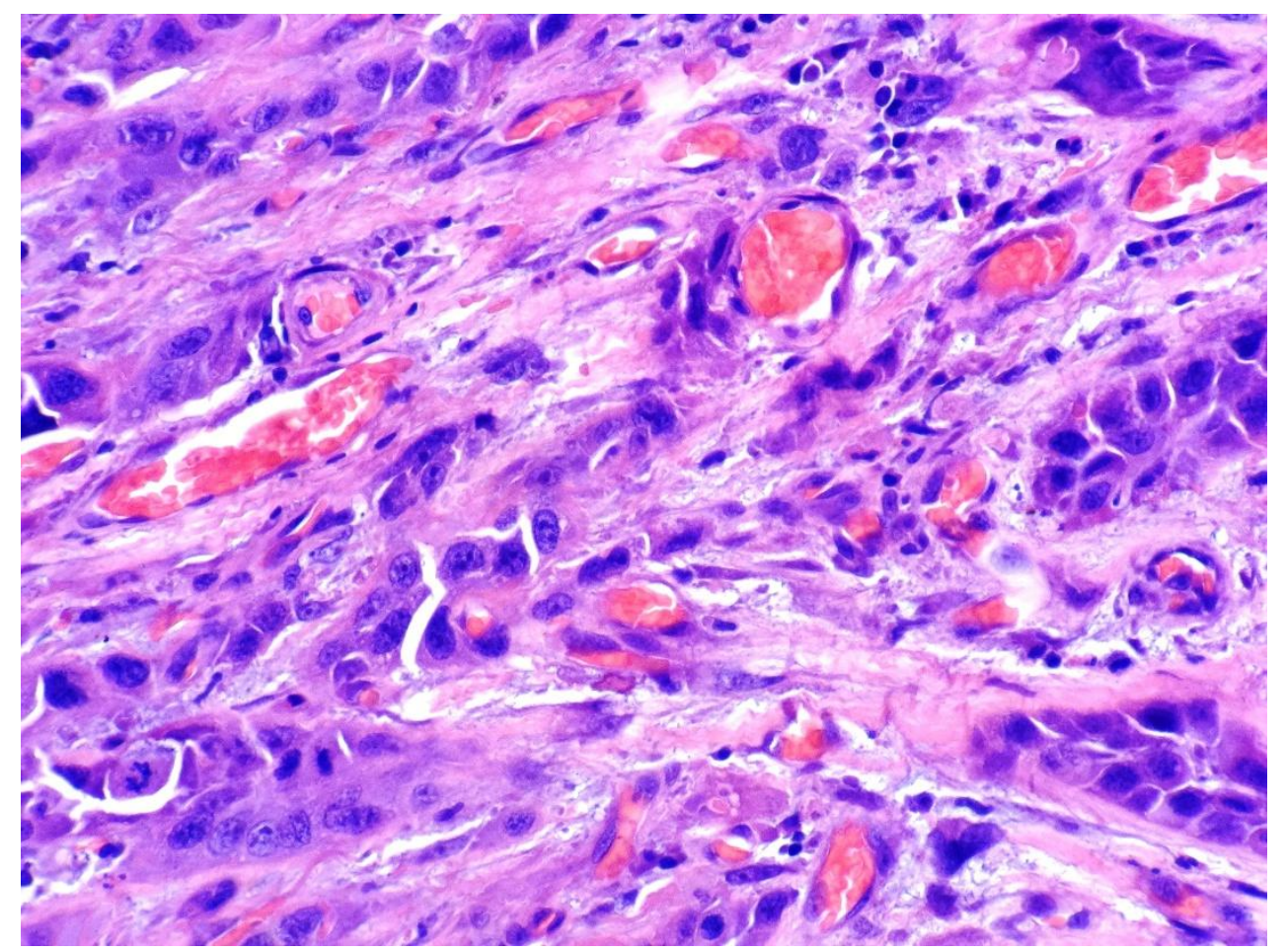

Figura 10 - Presença de necrose tumoral superficial. HE, 100x. 


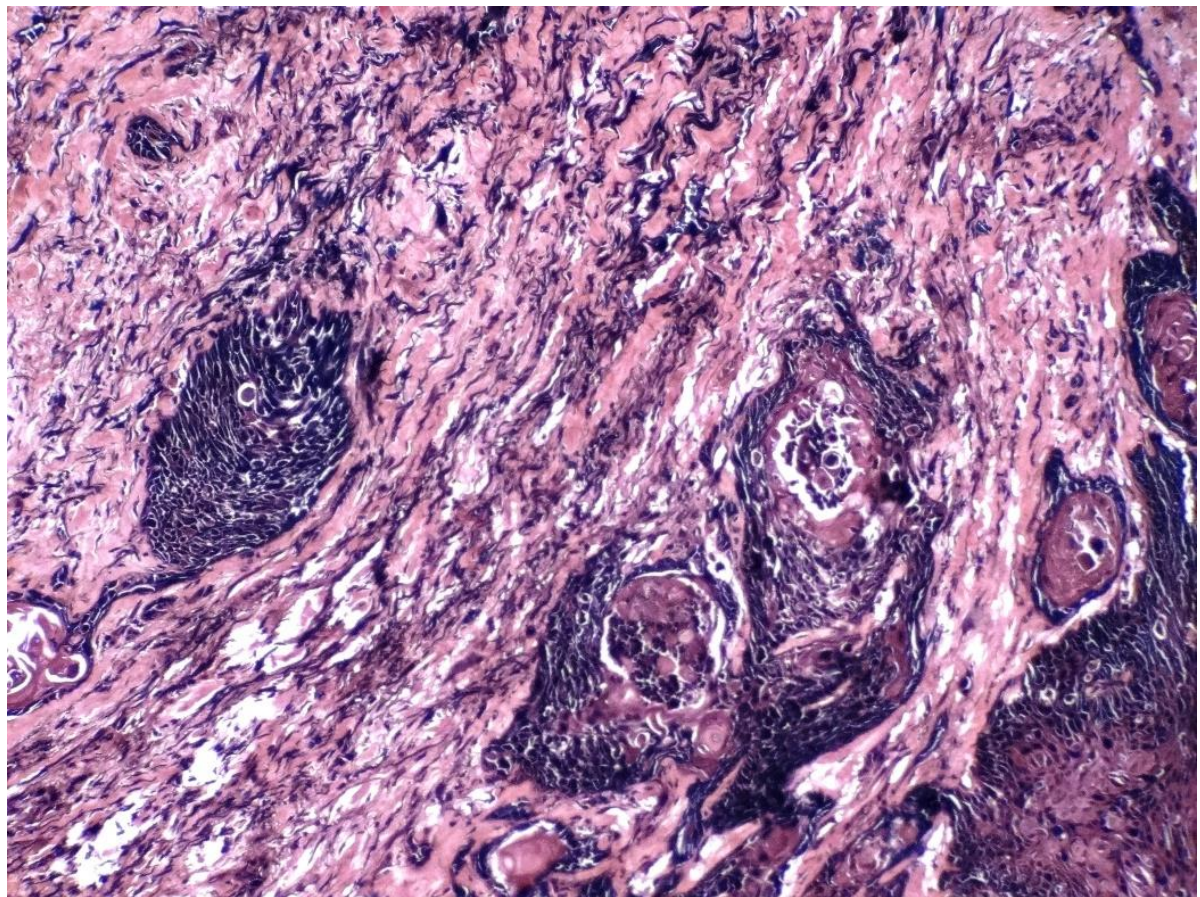

Figura 11 - Manutenção do arranjo de elastina. Verhoff, 20x.

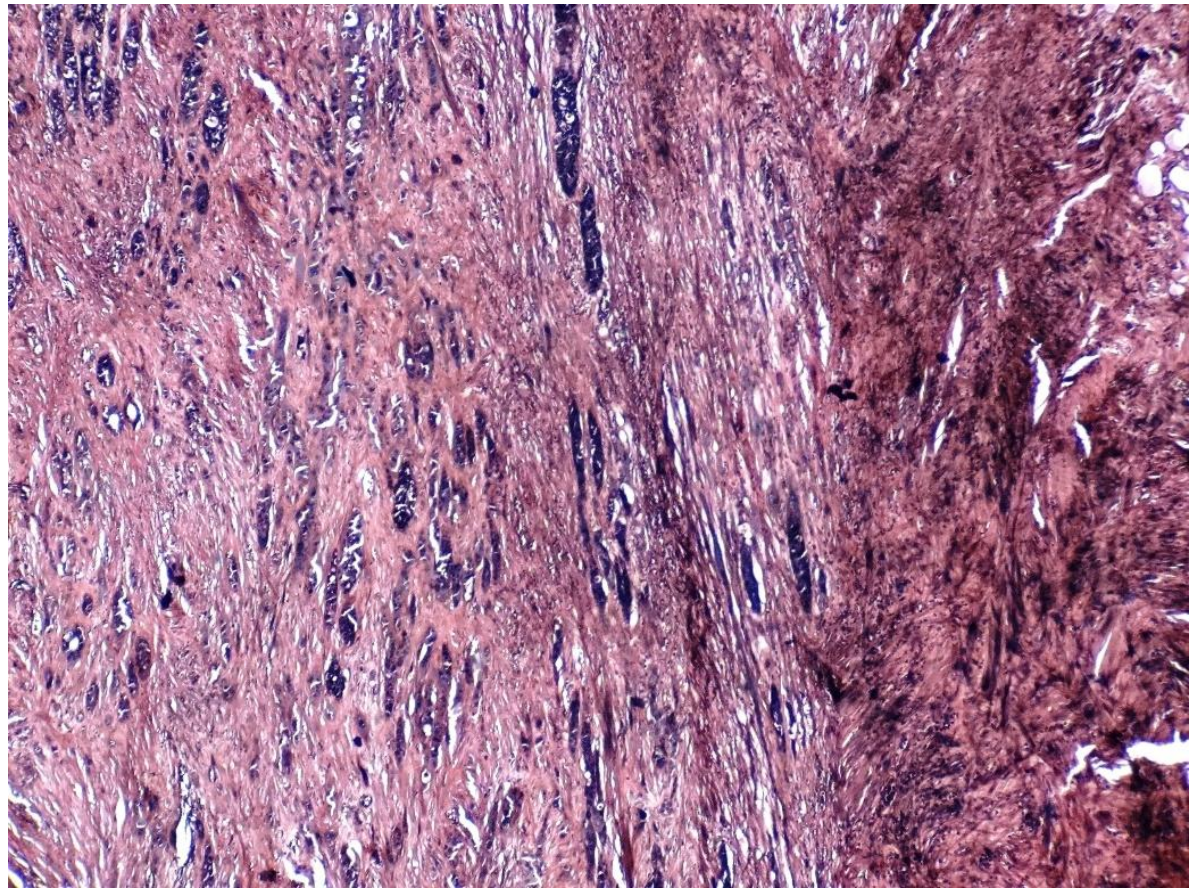

Figura 12 - Perda da elastina. Verhoff, 20x. 
As Tabelas 3 e 4 mostram associação entre as variáveis de acordo com a condição da comissura anterior. O status 3 da condição da comissura anterior apresenta pequena casuística (quatro casos). A Tabela 5 e 6 mostram as associações considerando-se o status 1 da comissura anterior versus status 2 e 3 agrupados.

Observaram-se medidas de idade maiores no status 1 da comissura anterior, diferença está marginalmente significativa $(p=0,092)$, demonstrado no gráfico 5 . O tempo de história anterior ao diagnóstico mostra medidas maiores no status 1 e essa associação foi estatisticamente significativa $(p=0,034)$, ilustrado no gráfico 6.

Das lesões unilaterais, 17 (85\%) delas tinham status 1 enquanto $11(39,3 \%)$ dos casos bilateral apresentavam status 2 e 3 . Essa associação mostrou-se marginalmente significativa $(p=0,068)$, visualizado no gráfico 7 .

Comparando os estádios T nos grupos, encontramos que 32 $(76,2 \%)$ dos pacientes em estádio T1b apresentaram status 1, e 4 $(67,7 \%)$ dos casos com estádio T2 eram status 2 e 3 . Essa diferença mostrou-se marginalmente significativa $(p=0,052)$, ilustrado no gráfico 8. Não se observaram associações com relação às demais variáveis das Tabelas 5 e 6. 
Tabela 3. Distribuição das variáveis demográficas e clínicas de acordo com condição da comissura anterior dos 48 pacientes.

\begin{tabular}{|c|c|c|c|c|}
\hline \multirow{3}{*}{$\begin{array}{l}\text { Variável } \\
\text { Gênero }\end{array}$} & \multirow{3}{*}{$\begin{array}{l}\text { Categoria / Medidas } \\
\text { Feminino } \\
\text { Masculino } \\
\end{array}$} & \multicolumn{3}{|c|}{ Status da Comissura Anterior } \\
\hline & & \multicolumn{3}{|c|}{ Freq. (\%) / Medidas } \\
\hline & & $\begin{array}{c}3(60,0) \\
31(721)\end{array}$ & $\begin{array}{l}1(20,0) \\
9(20,9)\end{array}$ & $\begin{array}{l}1(20,0) \\
3(7,0)\end{array}$ \\
\hline Idade (anos) & $\begin{array}{l}\mathrm{N} \\
\text { Variação } \\
\text { Mediana } \\
\text { Média (Desvio-padrão) }\end{array}$ & $\begin{array}{c}34 \\
42-77 \\
61,5 \\
62,7(7,9) \\
\end{array}$ & $\begin{array}{c}10 \\
40-63 \\
58,5 \\
55,7(8,1)\end{array}$ & $\begin{array}{c}4 \\
59-66 \\
62,0 \\
62,2(3,0)\end{array}$ \\
\hline Tabagismo & $\begin{array}{l}\text { Não } \\
\text { Sim }\end{array}$ & $\begin{array}{c}2(50,0) \\
32(72,7) \\
\end{array}$ & $\begin{array}{c}0(0,0) \\
10(22,7) \\
\end{array}$ & $\begin{array}{l}2(50,0) \\
2(4,6) \\
\end{array}$ \\
\hline Etilismo & $\begin{array}{l}\text { Não } \\
\text { Sim }\end{array}$ & $\begin{array}{c}25(69,4) \\
9(75,0) \\
\end{array}$ & $\begin{array}{l}8(22,2) \\
2(16,7) \\
\end{array}$ & $\begin{array}{l}3(8,3) \\
1(8,3) \\
\end{array}$ \\
\hline $\begin{array}{l}\text { Tempo de } \\
\text { história } \\
\text { (meses) }\end{array}$ & $\begin{array}{l}\mathrm{N} \\
\text { Variação } \\
\text { Mediana } \\
\text { Média (Desvio-padrão) }\end{array}$ & $\begin{array}{c}34 \\
1-24 \\
3,0 \\
5,2(4,2)\end{array}$ & $\begin{array}{c}10 \\
2-4 \\
3,0 \\
3,0(0,7)\end{array}$ & $\begin{array}{c}4 \\
2-4 \\
3,5 \\
3,2(1,0)\end{array}$ \\
\hline $\begin{array}{l}\text { Característica } \\
\text { da lesão }\end{array}$ & $\begin{array}{l}\text { Unilateral } \\
\text { Bilateral }\end{array}$ & $\begin{array}{l}17(85,0) \\
17(60,7) \\
\end{array}$ & $\begin{array}{l}2(10,0) \\
8(28,6)\end{array}$ & $\begin{array}{r}1(5,0) \\
3(10,7) \\
\end{array}$ \\
\hline Estádio T & $\begin{array}{l}1 b \\
2\end{array}$ & $\begin{array}{l}32(76,2) \\
2(33,3)\end{array}$ & $\begin{array}{l}8(19,0) \\
2(33,3)\end{array}$ & $\begin{array}{c}2(4,8) \\
2(33,3)\end{array}$ \\
\hline $\mathrm{RxT}$ & $\begin{array}{l}\text { Nao } \\
\text { Sim }\end{array}$ & $\begin{array}{l}32(74,4) \\
2(40,0) \\
\end{array}$ & $\begin{array}{l}9(20,9) \\
1(20,0) \\
\end{array}$ & $\begin{array}{r}2(4,7) \\
2(40,0) \\
\end{array}$ \\
\hline $\begin{array}{l}\text { Tempo de } \\
\text { seguimento } \\
\text { (meses) }\end{array}$ & $\begin{array}{l}\mathrm{N} \\
\text { Variação } \\
\text { Mediana } \\
\text { Media (Desvio Padrão) }\end{array}$ & $\begin{array}{c}34 \\
18-60 \\
36,5 \\
40,3(14,1) \\
\end{array}$ & $\begin{array}{c}10 \\
30-60 \\
43,0 \\
43,4(9,3) \\
\end{array}$ & $\begin{array}{c}4 \\
28-60 \\
41,0 \\
42,5(13,2) \\
\end{array}$ \\
\hline Status & $\begin{array}{l}\text { segunda lesão resgatada } \\
\text { óbito pelo câncer } \\
\text { Vivo sem evidência de doença } \\
\text { Recidiva local resgatada LT + } \\
\text { ECB }\end{array}$ & $\begin{array}{c}1(100,0) \\
1(50,0) \\
32(72,7) \\
0(0,0)\end{array}$ & $\begin{aligned} & (0,0) \\
0 & (0,0) \\
10 & (22,7) \\
0 & (0,0)\end{aligned}$ & $\begin{array}{c}0(0,0) \\
1(50,0) \\
2(4,6) \\
1(100,0)\end{array}$ \\
\hline
\end{tabular}


Tabela 4. Distribuição das variáveis patológicas de acordo com condição da comissura anterior dos 48 pacientes.

\begin{tabular}{|c|c|c|c|c|}
\hline \multirow{3}{*}{$\begin{array}{l}\text { Variável } \\
\text { Grau } \\
\text { histológico }\end{array}$} & \multirow{3}{*}{$\begin{array}{l}\text { Categoria / Medidas } \\
\text { I } \\
\text { II } \\
\text { II }\end{array}$} & \multirow{2}{*}{\multicolumn{3}{|c|}{$\begin{array}{c}\text { Status da comissura anterior } \\
1 \\
\text { Freq. (\%) / Medidas }\end{array}$}} \\
\hline & & & & \\
\hline & & $\begin{array}{l}8(66,7) \\
24(72,7) \\
2(66,7)\end{array}$ & $\begin{array}{l}2(16,7) \\
7(21,2) \\
1(33,3)\end{array}$ & $\begin{array}{l}2(16,7) \\
2(6,1) \\
0(0,0)\end{array}$ \\
\hline $\begin{array}{l}\text { Índice } \\
\text { mitótico }\end{array}$ & $\begin{array}{l}\text { N } \\
\text { Variação } \\
\text { Mediana } \\
\text { Média (Desvio-padrão) }\end{array}$ & $\begin{array}{c}34 \\
1-37 \\
7,0 \\
8,5(7,3)\end{array}$ & $\begin{array}{c}10 \\
1-15 \\
8,5 \\
8,1(5,2)\end{array}$ & $\begin{array}{c}4 \\
5-37 \\
14,5 \\
17,7 \\
(14,3)\end{array}$ \\
\hline $\begin{array}{l}\text { Irregularidade } \\
\text { nuclear }\end{array}$ & $\begin{array}{l}\text { Intensa } \\
\text { Moderada }\end{array}$ & $\begin{array}{l}15(71,4) \\
19(70,4)\end{array}$ & $\begin{array}{l}4(19,1) \\
6(22,2)\end{array}$ & $\begin{array}{l}2(9,5) \\
2(7,4)\end{array}$ \\
\hline $\begin{array}{l}\text { Nucléolo } \\
\text { evidente }\end{array}$ & $\begin{array}{l}\text { Ausente } \\
\text { Presente }\end{array}$ & $\begin{array}{l}21(67,7) \\
13(76,5)\end{array}$ & $\begin{array}{l}8(25,8) \\
2(11,8)\end{array}$ & $\begin{array}{c}2(6,5) \\
2(11,8)\end{array}$ \\
\hline $\begin{array}{l}\text { Necrose } \\
\text { tumoral }\end{array}$ & $\begin{array}{l}\text { Ausente } \\
\text { Presente }\end{array}$ & $\begin{array}{l}33(70,2) \\
1(100,0)\end{array}$ & $\begin{array}{c}10(21,3) \\
0(0,0)\end{array}$ & $\begin{array}{l}4(8,5) \\
0(0,0)\end{array}$ \\
\hline $\begin{array}{l}\text { Necrose } \\
\text { superficial }\end{array}$ & $\begin{array}{l}\text { Ausente } \\
\text { Presente }\end{array}$ & $\begin{array}{l}32(69,6) \\
2(100,0)\end{array}$ & $\begin{array}{c}10(21,7) \\
0(0,0)\end{array}$ & $\begin{array}{l}4(8,7) \\
0(0,0)\end{array}$ \\
\hline
\end{tabular}


Tabela 5. Distribuição das variáveis demográficas e clínicas de acordo com condição da comissura anterior dos 48 pacientes.

\begin{tabular}{|c|c|c|c|c|}
\hline Variável & Categoria / Medidas & $\begin{array}{l}\text { Status d } \\
\quad \text { ar } \\
\mathbf{1} \\
\text { Freq. } \%\end{array}$ & $\begin{array}{l}\text { comissura } \\
\text { terior } \\
2 \text { e } 3 \\
\text { / Medidas }\end{array}$ & p-valor \\
\hline Gênero & $\begin{array}{l}\text { Feminino } \\
\text { Masculino }\end{array}$ & $\begin{array}{c}3(60,0) \\
31(72,1) \\
\end{array}$ & $\begin{array}{c}2(40,0) \\
12(27,9) \\
\end{array}$ & 0,621 \\
\hline Idade (anos) & $\begin{array}{l}\mathrm{N} \\
\text { Variação } \\
\text { Mediana } \\
\text { Media (Desvio-padrão) }\end{array}$ & $\begin{array}{c}34 \\
42-77 \\
61,5 \\
62,7(7,9)\end{array}$ & $\begin{array}{c}14 \\
40-66 \\
60,0 \\
57,6(7,5)\end{array}$ & 0,092 * \\
\hline Tabagismo & $\begin{array}{l}\text { Não } \\
\text { Sim }\end{array}$ & $\begin{array}{c}2(50,0) \\
32(72,7)\end{array}$ & $\begin{array}{c}2(50,0) \\
12(27,3)\end{array}$ & 0,569 \\
\hline Etilismo & $\begin{array}{l}\text { Não } \\
\text { Sim }\end{array}$ & $\begin{array}{c}25(69,4) \\
9(75,0)\end{array}$ & $\begin{array}{c}11(30,6) \\
3(25,0)\end{array}$ & 0,999 \\
\hline $\begin{array}{l}\text { Tempo de } \\
\text { história } \\
\text { (meses) }\end{array}$ & $\begin{array}{l}\mathrm{N} \\
\text { Variação } \\
\text { Mediana } \\
\text { Média (Desvio-padrão) }\end{array}$ & $\begin{array}{c}34 \\
1-24 \\
3,0 \\
5,2(4,2) \\
\end{array}$ & $\begin{array}{c}14 \\
2-4 \\
3,0 \\
3,1(0,7) \\
\end{array}$ & 0,034 \\
\hline $\begin{array}{l}\text { Característica } \\
\text { da lesão }\end{array}$ & $\begin{array}{l}\text { Unilateral } \\
\text { Bilateral }\end{array}$ & $\begin{array}{l}17(85,0) \\
17(60,7) \\
\end{array}$ & $\begin{array}{c}3(15,0) \\
11(39,3) \\
\end{array}$ & $0,068^{* *}$ \\
\hline Estádio T & $\begin{array}{l}1 b \\
2\end{array}$ & $\begin{array}{l}32(76,2) \\
2(33,3)\end{array}$ & $\begin{array}{c}10(23,8) \\
4(66,7)\end{array}$ & 0,052 \\
\hline Radioterapia & $\begin{array}{l}\text { Não } \\
\text { Sim }\end{array}$ & $\begin{array}{c}32(74,4) \\
2(40,0)\end{array}$ & $\begin{array}{c}11(25,6) \\
3(60,0) \\
\end{array}$ & 0,140 \\
\hline $\begin{array}{l}\text { Tempo de } \\
\text { seguimento } \\
\text { (meses) }\end{array}$ & $\begin{array}{l}\mathrm{N} \\
\text { Variação } \\
\text { Mediana } \\
\text { Média (Desvio-padrão) }\end{array}$ & $\begin{array}{c}34 \\
18-60 \\
36,5 \\
40,3(14,1)\end{array}$ & $\begin{array}{c}14 \\
28-60 \\
42,0 \\
43,1(10,0)\end{array}$ & $0,501 * * *$ \\
\hline $\begin{array}{l}\text { Condição do } \\
\text { paciente }\end{array}$ & $\begin{array}{l}\text { segunda lesão resgatada } \\
\text { óbito pelo câncer } \\
\text { Vivo sem evidência de doença } \\
\text { Recidiva local resgatada LT + } \\
\text { ECB }\end{array}$ & $\begin{array}{c}1(100,0) \\
1(50,0) \\
32(72,7) \\
0(0,0)\end{array}$ & $\begin{array}{c}0(0,0) \\
1(50,0) \\
12(27,3) \\
1(100,0)\end{array}$ & NA \\
\hline
\end{tabular}

p-valor obtido pelo teste exato de Fisher; NA: Não avaliável estatisticamente * $p$-valor obtido pelo teste $U$ de Mann-Whitney ${ }^{\star *} p$-valor obtido pelo teste de frequências do qui-quadrado; ${ }^{* * *} \mathrm{p}$-valor obtido pelo teste t de Student. 
Tabela 6. Distribuição das variáveis patológicas de acordo com a condição da comissura anterior dos 48 pacientes

\begin{tabular}{|c|c|c|c|c|}
\hline \multirow[t]{2}{*}{ Variável } & \multirow[t]{2}{*}{ Categoria / Medidas } & \multicolumn{2}{|c|}{$\begin{array}{c}\text { Status da Comissura } \\
\text { Anterior }\end{array}$} & \multirow[t]{2}{*}{ p-valor } \\
\hline & & $\begin{array}{l}1 \\
\text { Freq. (\%) }\end{array}$ & $\begin{array}{c}2 \text { e } 3 \\
\text { Medidas }\end{array}$ & \\
\hline Grau histológico & $\begin{array}{l}\text { I } \\
\text { II } \\
\text { II }\end{array}$ & $\begin{array}{l}8(66,7) \\
24(72,7) \\
2(66,7) \\
\end{array}$ & $\begin{array}{l}4(33,3) \\
9(27,3) \\
1(33,3) \\
\end{array}$ & NA \\
\hline Índice mitótico & $\begin{array}{l}\mathrm{N} \\
\text { Variação } \\
\text { Mediana } \\
\text { Média (Desvio-padrão) }\end{array}$ & $\begin{array}{c}34 \\
1-37 \\
7,0 \\
8,5(7,3) \\
\end{array}$ & $\begin{array}{c}14 \\
1-37 \\
9,5 \\
10,8(9,3) \\
\end{array}$ & 0,385 \\
\hline $\begin{array}{l}\text { Irregularidade } \\
\text { nuclear }\end{array}$ & $\begin{array}{l}\text { Intensa } \\
\text { Moderada }\end{array}$ & $\begin{array}{l}15(71,4) \\
19(70,4) \\
\end{array}$ & $\begin{array}{l}6(28,6) \\
8(29,6) \\
\end{array}$ & 0,936 * \\
\hline Nucléolo evidente & $\begin{array}{l}\text { Ausente } \\
\text { Presente }\end{array}$ & $\begin{array}{l}21(67,7) \\
13(76,5) \\
\end{array}$ & $\begin{array}{c}10(32,3) \\
4(23,5)\end{array}$ & 0,525 * \\
\hline Necrose tumoral & $\begin{array}{l}\text { Ausente } \\
\text { Presente }\end{array}$ & $\begin{array}{l}33(70,2) \\
1(100,0) \\
\end{array}$ & $\begin{array}{c}14(29,8) \\
0(0,0) \\
\end{array}$ & NA \\
\hline Necrose superficial & $\begin{array}{l}\text { Ausente } \\
\text { Presente }\end{array}$ & $\begin{array}{l}32(69,6) \\
2(100,0)\end{array}$ & $\begin{array}{c}14(30,4) \\
0(0,0)\end{array}$ & NA \\
\hline
\end{tabular}

NA: Não avaliável estatisticamente; $p$-valor obtido pelo teste $U$ de MannWhitney ; * $p$-valor obtido pelo teste de frequências do qui-quadrado. 
Gráfico 1. Distribuição do status da comissura anterior pela idade

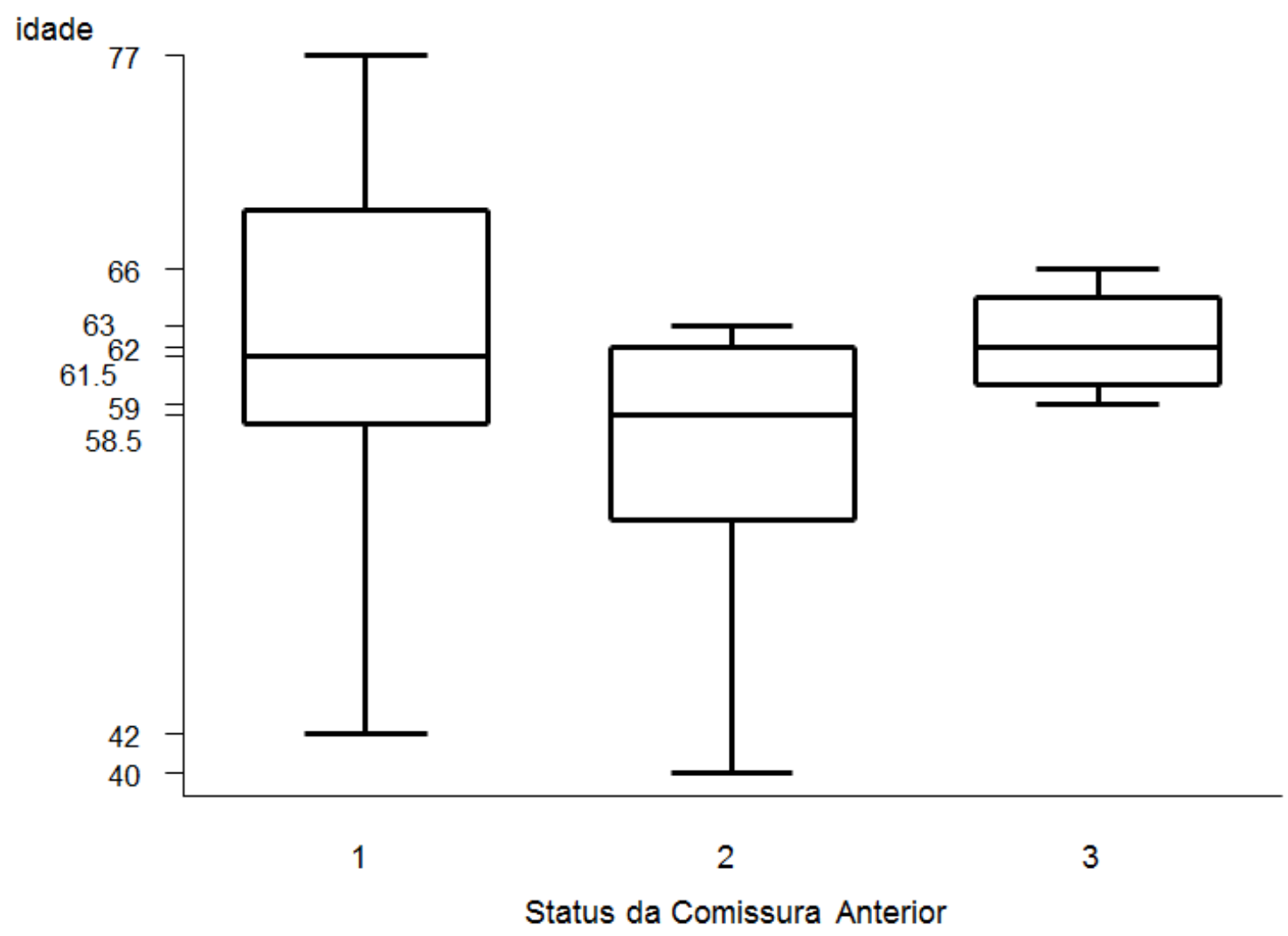

Gráfico 2. Distribuição do status da comissura anterior pelo tempo de história tempo hist. (meses)

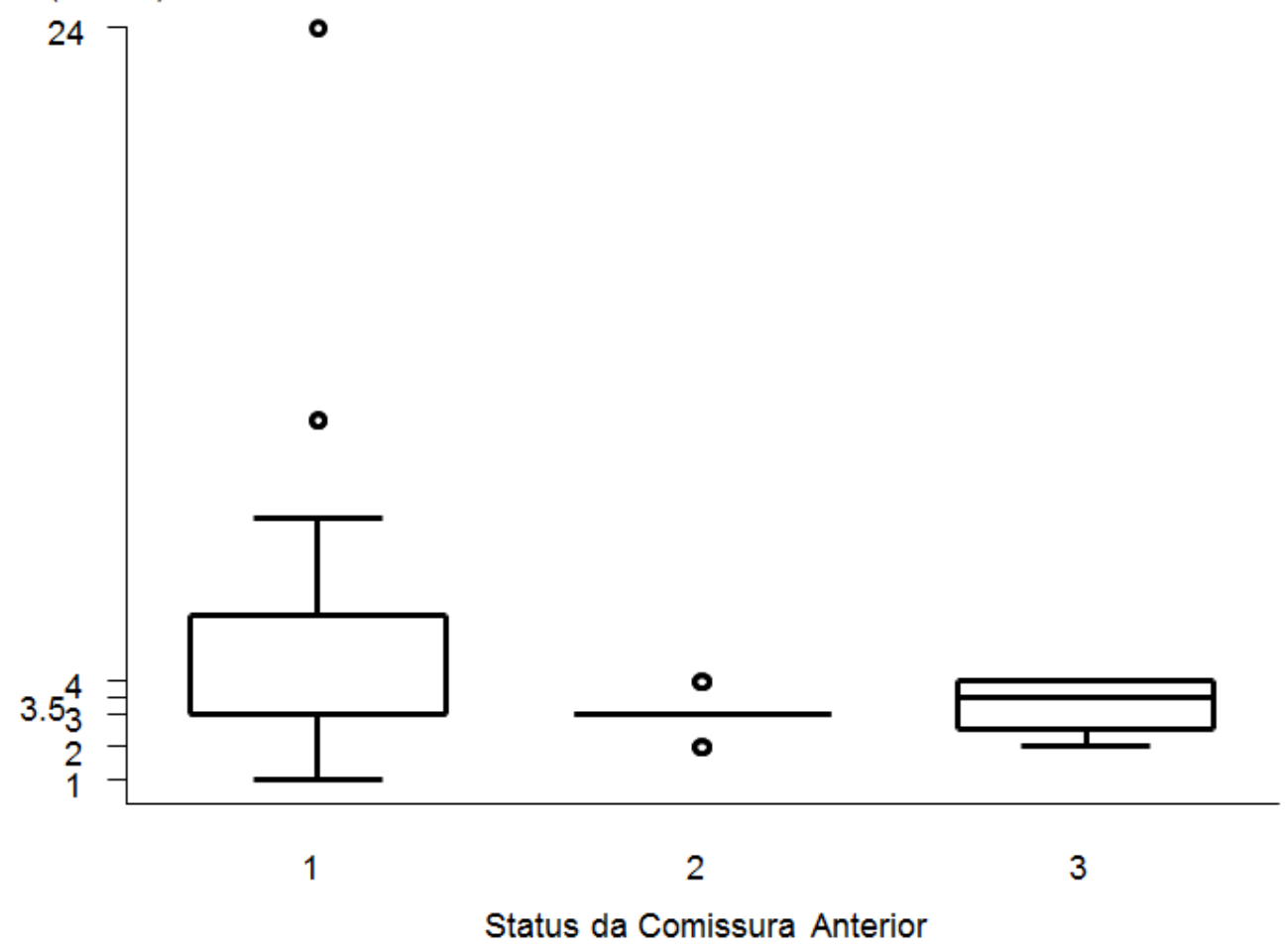


Gráfico 3. Distribuição do status da comissura anterior pela localização da lesão

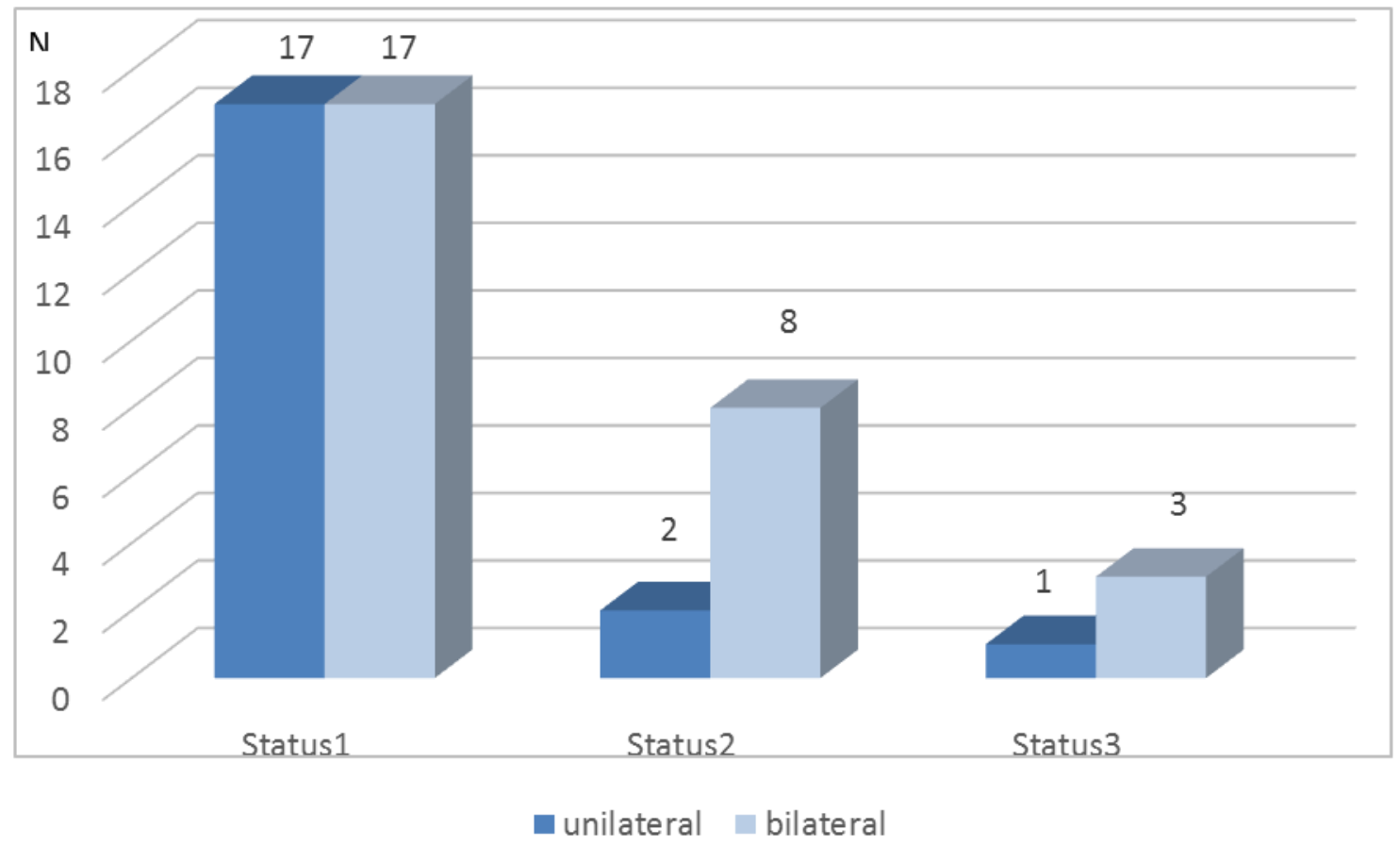

Gráfico 4. Distribuição do status da comissura anterior pelo estádio T

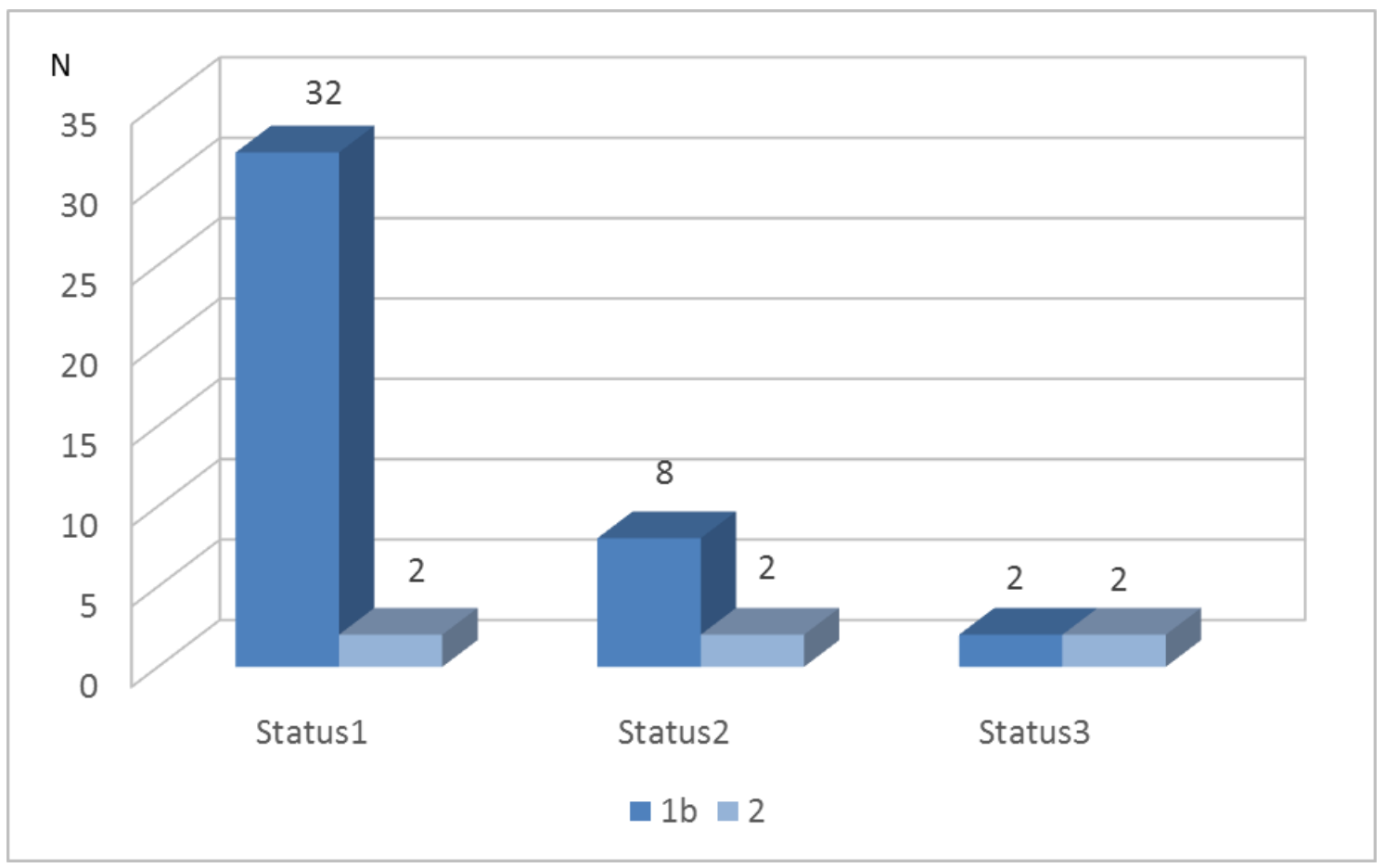


Gráfico 5. Distribuição do status da comissura anterior pela idade

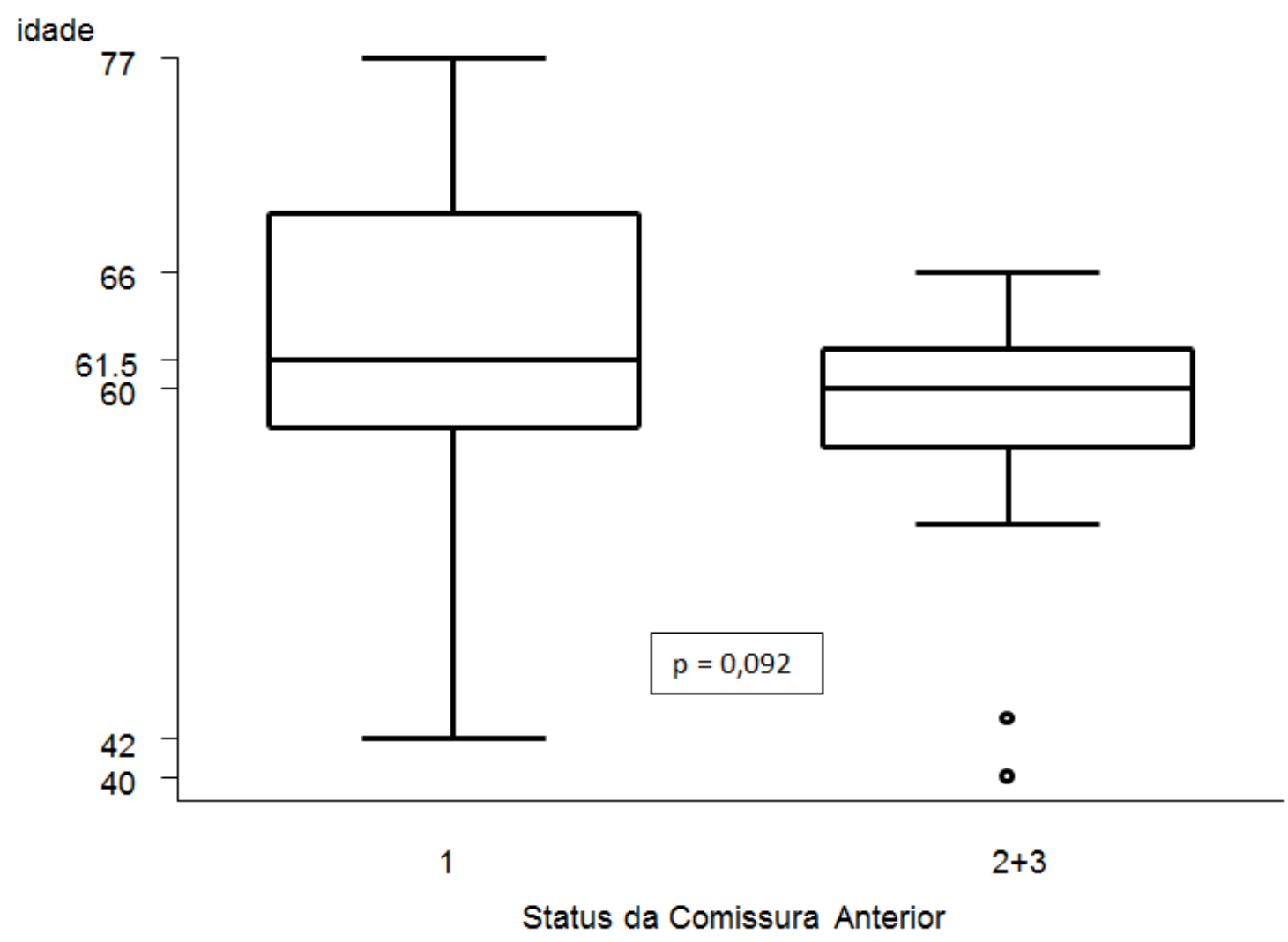

Gráfico 6. Distribuição do status da comissura anterior pela idade

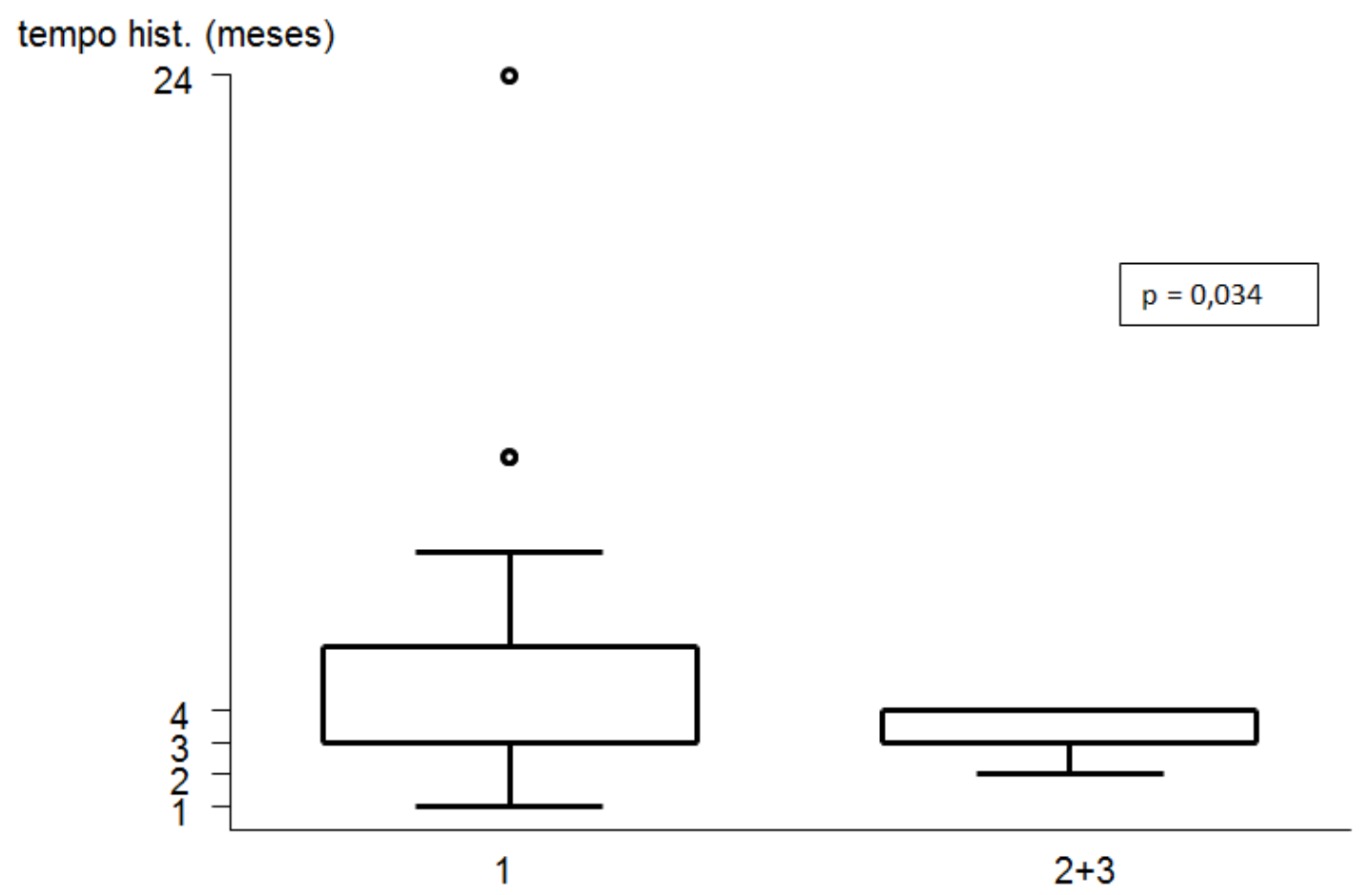

Status da Comissura Anterior 
Gráfico 7. Distribuição do status da comissura anterior pela localização da lesão

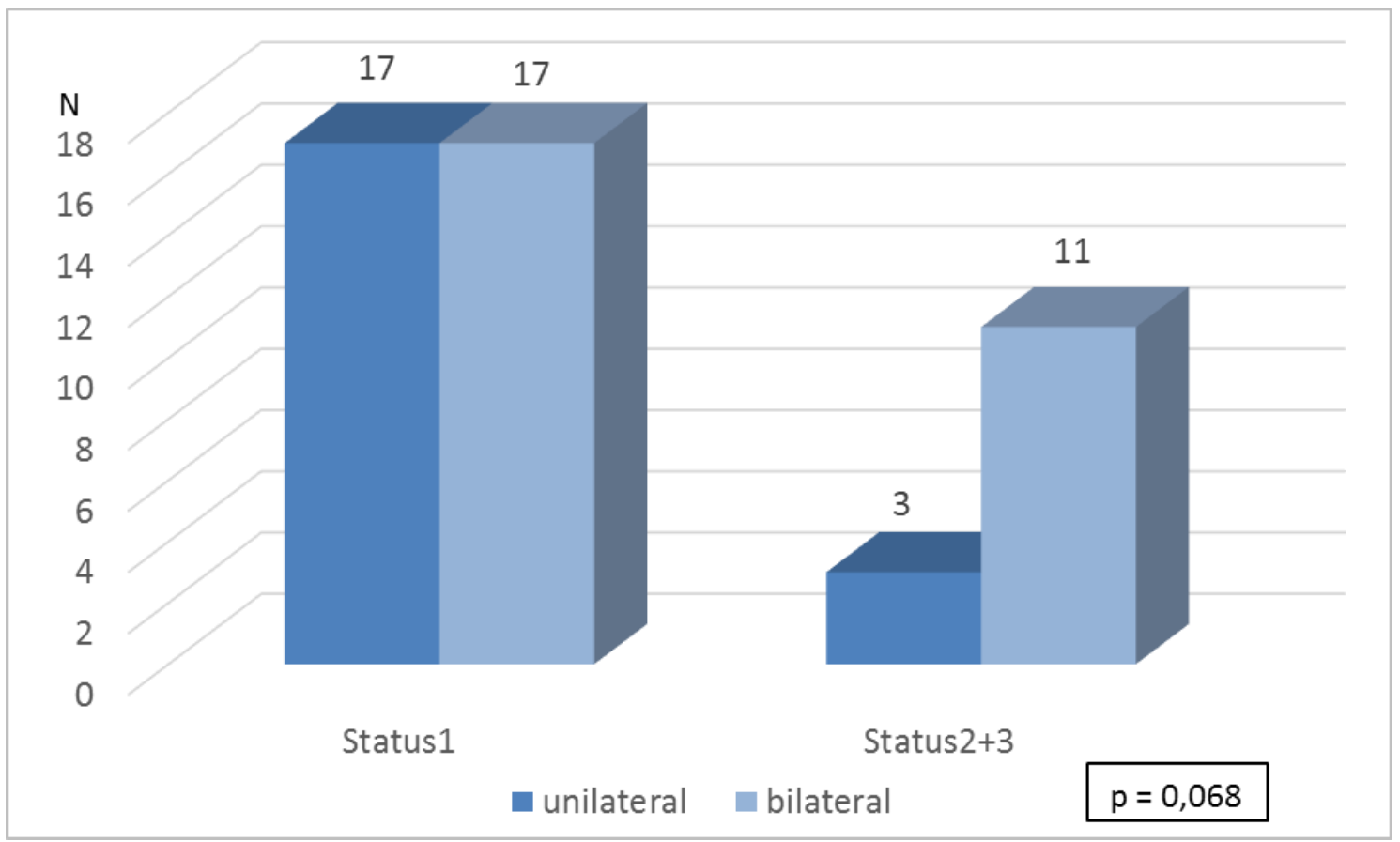

Gráfico 8. Distribuição do status da comissura anterior pelo estádio T

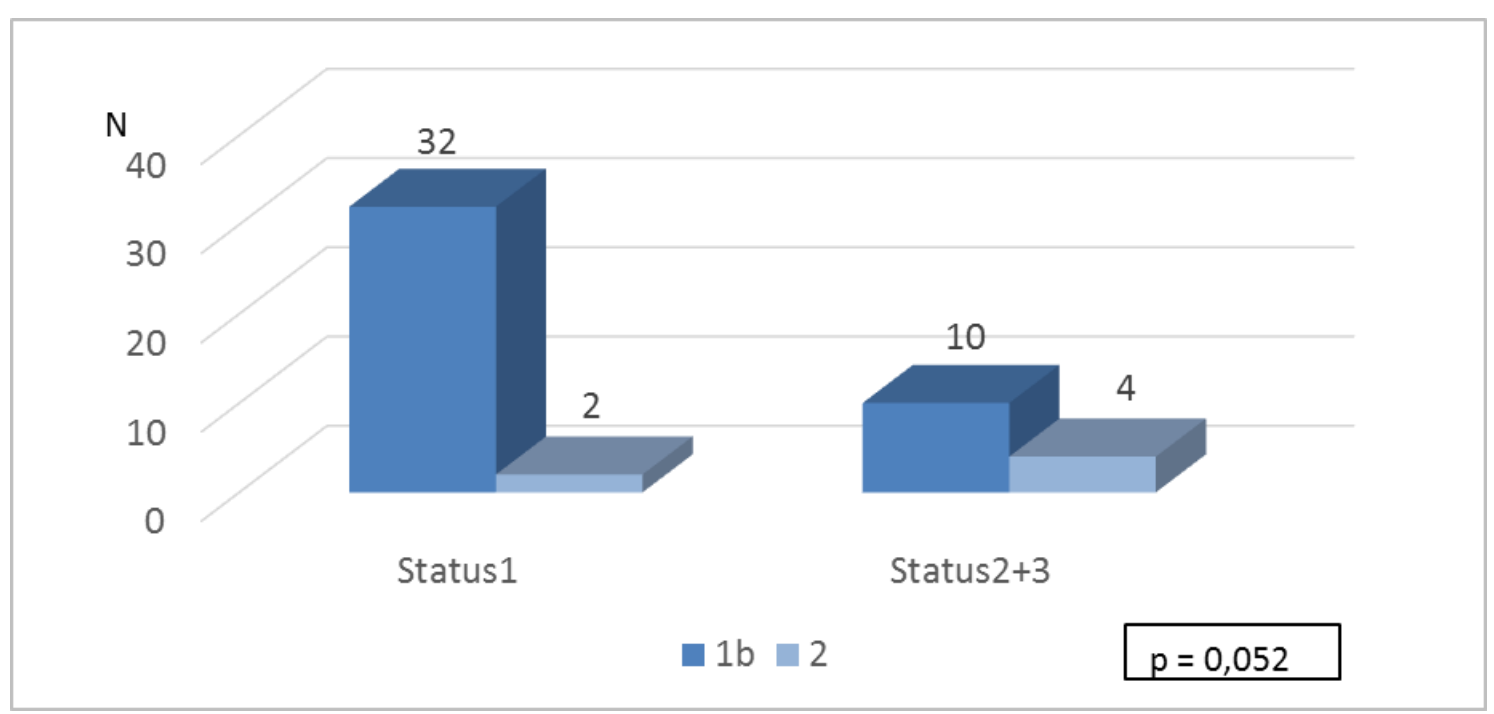




\section{DISCUSSÃO}

A comissura anterior é uma área com especial interesse na análise de neoplasias malignas da laringe. Nos cânceres glóticos, o acometimento dessa região é apontado como fator de mau prognóstico ao tratamento instituído ${ }^{7-9,24,26,35,36,38,40,42,50-52,54,57,61}$. Uma explicação para esse fato é a possibilidade da ocorrência de invasão neoplásica da cartilagem tireoidea $a^{1,24,26,37,38,42}$.

Em 2000, Rifai e Khattab encontraram infiltração microscópica da cartilagem tireoidea em todos os 30 casos analisados $^{37}$. No presente estudo, foram encontrados quatro $(8,3 \%)$ casos com infiltração microscópica da cartilagem. Dado semelhante foi publicado por Hartl et al., em 2012, com prevalência geral de invasão da cartilagem tireoidea de $8,5 \%{ }^{54}$. Em 2013, Szyfter et al. observaram taxa de invasão cartilaginosa em 3,7\% dos $\operatorname{casos}^{55}$. Ulusan et al. encontraram taxa de invasão da cartilagem de 5,4\% nos casos restritos a glote e taxa de $32 \%$ nos casos com extensão supraglótica ${ }^{62}$.

Agrupando os espécimes com neoplasia adjacente à cartilagem com os que apresentaram infiltração cartilaginosa (status 2 e 3), foram totalizados $14(29,1 \%)$ casos. Não houve diferença estatística nos desfechos com ou sem infiltração tumoral. Diferente 
do verificado neste estudo, Fiorella et al. observaram que a infiltração microscópica da comissura anterior estava associada a um maior número de recorrências locais $(25,5 \% \text { vs. } 5 \%)^{24}$. Hartl et al. encontraram a taxa de controle local de $94 \%$ para as neoplasia sem invasão da cartilagem e $83 \%$ para aqueles com invasão ${ }^{54}$, contrastando com nossos achados.

Como a ocorrência de infiltração microscópica da cartilagem tireoidea pelo carcinoma foi incomum (8,3\%), provavelmente os demais casos seriam elegíveis à microcirurgia endoscópica a laser (MEL), desde que a exposição endoscópica fosse adequada. A cirurgia aberta, no caso com a realização da laringectomia frontolateral, inclui a excisão da quilha da cartilagem, portanto, agregando ao espécime a área de infiltração tumoral cartilaginosa quando esta está presente. Isso justificaria os resultados oncológicos semelhantes em nosso grupo de estudo, independente da relação entre tumor e cartilagem. Person e Salassa descreveram 23 pacientes com câncer glótico T1 ou T2 com acometimento da comissura anterior, sendo que nenhum deles apresentou recorrência local com a realização de $\mathrm{MEL}^{43}$. Zeitels et al. concluíram que o envolvimento da comissura anterior (22 de 32 casos) não influenciou o controle local. Todos os casos tratados pela técnica a laser ficaram livres do câncer sem a necessidade de 
radioterapia ou cirurgia aberta ${ }^{70}$. Já Steiner et al. relataram 263 pacientes com câncer glótico T1 ou T2 submetidos à MEL, com recorrência de $24 \%$ com acometimento da comissura anterior e $7 \%$ sem envolvimento ${ }^{14}$. Peretti et al. encontraram $24 \%$ de local recorrência nos pacientes com envolvimento do terço anterior da prega vocal $^{40}$. Sachse et al. encontraram controle local significativamente inferior quando a comissura anterior estava acometida, em pacientes com câncer T1 e T2 tratados com laringectomia parcial ou MEL. Todavia, os autores não encontraram diferença estatística comparando os grupos submetidos à laringectomia parcial externa ou à $\mathrm{MEL}^{51}$. Mizrachi et al. analisaram o insucesso da MEL para o câncer glótico precoce e concluíram que recorrência local era superior quando havia o acometimento da comissura anterior ${ }^{57}$.

A baixa frequência de infiltração microscópica da cartilagem tireoidea também favoreceria a radioterapia como opção terapêutica. Contudo, Maheshwar e Gaffney mostraram piores resultados da RT em pacientes com câncer glótico em estádio T1 com envolvimento da comissura anterior quando comparados àqueles sem seu envolvimento ${ }^{9}$. Igual conclusão tiveram Nozaki et al., relatando um controle local de $89 \%$ sem envolvimento da comissura anterior e 58\% no grupo $\mathrm{com}^{38}$ e Tong et al., com 
controle local de $95 \%$ na ausência do acometimento da comissura anterior e de $86 \%$ quando envolvia a comissura anterior $(p=0,011)^{52}$. Kitani et al. também identificaram que o envolvimento da comissura anterior foi fator prognóstico estatisticamente relevante no controle neoplásico local $(91 \% \text { vs. } 51 \%)^{63}$.

Já Persky et al. conseguiram controle local de 88\% em 35 pacientes com câncer glótico(T1 e T2) acometendo comissura anterior e tratados com $\mathrm{RT}^{39}$. Al-Mamgani et al. mostraram controle local similares nos grupos com ou sem envolvimento da comissura anterior $(84 \% \text { e } 86 \% \text {, respectivamente })^{71}$. Nur et al. também não encontraram diferença estatística no impacto do acometimento da comissura anterior após analise multivariada ${ }^{47}$.

Também não houve relação entre as características patológicas analisadas e a presença de infiltração cartilaginosa. O grau de diferenciação histológica, índice mitótico, irregularidade nuclear, presença de nucléolo e necrose tumoral não foram fatores determinantes. Análise semelhante foi realizada por Leszcznska et al., em 2015. Os autores fizerem uma análise histopatológica de 254 pacientes, os autores encontraram 16 casos de metástase prélaríngea, infiltração pericondrial em 11 pacientes, oito casos de invasão do tecido cartilaginoso, dois pacientes com invasão de microvasos e um com infiltração perineural. Apenas a metástase 
pré-laríngea piorou as taxas de controle local e de sobrevida em cinco anos. Os autores não encontraram diferença estatística quando compararam as outras alterações histológicas adversas e pacientes sem elas ${ }^{59}$.

As medidas de idade foram maiores quando a cartilagem estava livre, diferença esta marginalmente significativa $(p=0,092)$. Provavelmente, um aumento da amostra poderia confirmar esta relação. O tempo de história anterior ao diagnóstico também foi maior nos casos com cartilagem livre $(p=0,034)$.

As lesões bilaterais estavam mais frequentemente associadas à infiltração ou adjacência tumoral à cartilagem em comparação as lesões unilaterais. Essa associação mostrou-se marginalmente significativa $(p=0,068)$. Novamente, um aumento da amostra poderia confirmar está relação. Também houve relação marginalmente significativa $(p=0,052)$ entre infiltração ou adjacência tumoral com os casos estadiados como T2. Uma possível explicação para estas associações seria que tumores bilaterais e/ou T2 são localmente mais avançados. 
7 CONCLUSÃO 


\section{CONCLUSÃO}

A infiltração da cartilagem tireoidea ocorreu em $8,3 \%$ dos tumores glóticos precoces com envolvimento da comissura anterior e não teve impacto no desfecho da população submetida à laringectomia fronto-lateral. A avaliação de características clínicas e histopatológicas dos tumores não apresentou significado estatístico. 
ANEXOS 


\section{Anexo 1}

Ref. Solicitação de execução de estudo: Invasão da cartilagem tireóide no tumor precoce de andar glótico acometendo a comissura anterior

Pesquisador responsável: Dr.Marco Aurelio V. Kulcsar/ Dr. Henrique W. Sava

\section{CONSIDERAÇÕES}

Estudo retrospectivo com finalidade para pesquisa para Mestrado. Objetivo avaliar o acometimento por tumor da cartilagem da comissura anterior em espécimes cirúrgicos de laringectomias fronto-laterais, correlacionando-as com dados clínicopatológicos do paciente. Serão avaliadas as lâminas histopatológicas dos espécimes cirúrgicos dos pacientes submetidos à laringectomia fronto lateral por carcinoma espinocelular precoce de laringe, estadiados clinicamente como T1b/T2.

\section{RESPONSABILIDADES DO PESQUISADOR}

Antes do início dos procedimentos relacionados ao estudo:

- Iniciar as atividades do estudo somente após aprovação/ciência do Comitê de Ética em Pesquisa para execução no ICESP segundo a Res. 196/96;

- Após aprovação do CEP, fornecer cópia da Carta de Aprovação e Relatório Semestral com ciência do CEP ao NP- ICESP;

- Enviar Publicação dos resultados do estudo;

Informamos que sua solicitação foi DEFERIDA.

Atenciosamente,

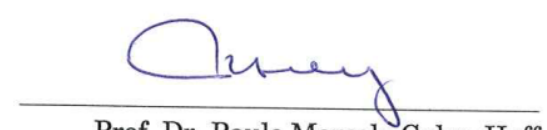

Prof. Dr. Paulo Marcelo Gehm Hoff

Diretor Geral em Exercício

$$
\begin{aligned}
& \text { Prof. Dr. Paulo M. G. Hoff } \\
& \text { Diretor Geral em Exercicio } \\
& \text { ICESP }
\end{aligned}
$$

\section{$\begin{array}{lll}\text { MEDICINA } & \text { SECRETARIA } & \text { GOYERNODOESTADO } \\ \text { DASAUDE } & \text { SAOPAULO }\end{array}$}




\section{Anexo 2}

\section{HOSPITAL DAS CLÍNICAS DA FACULDADE DE MEDICINA DA USP - HCFMUSP}

\section{PARECER CONSUBSTANCIADO DO CEP}

\section{DADOS DO PROJETO DE PESQUISA}

Título da Pesquisa: Invasăo da cartilagem tireóide no tumor precoce de andar glótico acometendo a comissura anterior

Pesquisador: Rogerio Aparecido Dedivitis

Área Temática:

Versão: 3

CAAE: 13497813.3 .0000 .0068

Instituição Proponente:Hospital das Clínicas da Faculdade de Medicina da USP

Patrocinador Principal: Financiamento Próprio

\section{DADOS DO PARECER}

Número do Parecer: 426.662

Data da Relatoria: 18/10/2013

Apresentaçäo do Projeto:

Trata-se de projeto retrospectivo baseado em análise de prontuários, e revisăo exames de espécimes anatomopatológicos produtos de laringectomias fronto-laterais por carcinoma de laringe.

\section{Objetivo da Pesquisa:}

Avaliar o acometimento por tumor da cartilagem da comissura anterior em espécimes cirúrgicos de laringectomias fronto-laterais, correlacionando-as com dados clínico-patológicos dos pacientes.

\section{Avaliação dos Riscos e Beneficios:}

A avaliação da frequência do acometimento da cartilagem tireóide na comissura anterior por neoplasia laringea, indicaria o quanto podem ser seguros os procedimentos que poupam a cartlagem (microcirurgia e radioterapia). permitindo ou näo um maior uso dessas técnicas nos casos de pacientes com carcinoma precoce de laringe com acometimento de comissura anterior. Näo há riscos, uma vez que se trata de estudo retrospectivo de espécimes de doentes anteriormente submetidos às cirurgias.

Comentários e Considerações sobre a Pesquisa:

Trata-se de pesquisa embasada na revisão e análise histopatológica de espécimes de

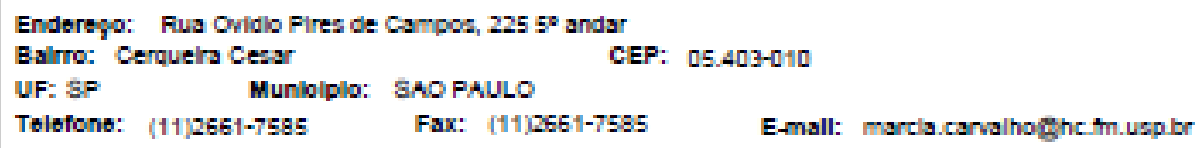




\section{HOSPITAL DAS CLÍNICAS DA FACULDADE DE MEDICINA DA USP - HCFMUSP}

Corthuaço do Partecer: 428602

laringectomia, procedentes de três diferentes hospitais: Hospital das Clínicas FMUSP, Instituto do câncer de Săo Paulo e Hospital Ana Costa. $O$ pesquisador já enviou manifestaçăo de anuência da Divisăo de Anatomia patológica/grupo de patologistas envolvidos no projeto. Informou o custo da relizaçăo de uma lâmina histopatológica. Serâo analisados/revisados 100 casos (numa base aproximada de 3 blocos/paciente da área de interesse, seria um total de 300 blocos, com cortes semi-seriados em 3 niveis de cada bloco: 900 novas lâminas - total de $\mathrm{R} \$ 3.600,00$ para os procedimentos técnicos de histopatologia).

Considerações sobre os Termos de apresentação obrigatória:

Trata-se de estudo retrospectivo de análise de prontuários e revisão de exames histopatológicos. 0 pesquisador justifica a solicitação da dispensa do TCLE.

Recomendaçöes:

O Pesquisador atendeu as recomendações formuladas.

Conclusöes ou Pendẻncias e Lista de Inadequações:

Näo há pendências. Entretanto, o orçamento deve ser informado no arquivo "Informaçöes Básicas sobre o Projeto".

Situação do Parecer:

Aprovado

Necessita Apreciaçäo da CONEP:

Nảo

Considerações Finais a critério do CEP:

Em conformidade com a Resolução CNS $n^{\circ} 466 / 12$ ¿ cabe ao pesquisador- a) desenvolver o projeto conforme delineado; b) elaborar e apresentar relatórios parciais e final; c)apresentar dados solicitados pelo CEP. a qualquer momento; d) manter em arquivo sob sua guarda, por 5 anos da pesquisa, contendo fichas individuais e todos os demais documentos recomendados pelo CEP; e) encaminhar os resultados para publicação, com os devidos créditos aos pesquisadores associados e ao pessoal técnico participante do projeto; f) justificar perante ao CEP interrupçäo do projeto ou a não publicaçäo dos resultados.

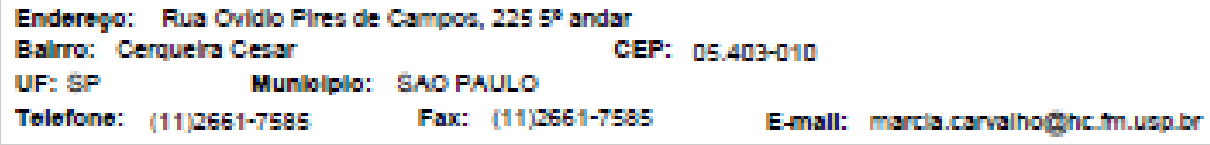


HOSPITAL DAS CLÍNICAS DA

FACULDADE DE MEDICINA DA USP - HCFMUSP

Centinuachas do Parecer: 4286062

SAO PAULO, 17 de Outubro de 2013

Assinador por:

Luiz Eugênio Garcez Leme

(Coordenador)

Enderego: Rua Ovidlo Fires de Campos, $2255^{\circ}$ andar

Balrro: Cerqueira Ceasr

CEP: $05.403-010$

UF: SP

Muniolplo: SAO PAULO

Tolofone: (11)2661-7585

Fax: (11),2661-7985

E-mall: marcia.carvalhoghe m.usp.br

Plaina os de do 


\section{Anexo 3 - Protocolo de pesquisa}

\section{Protocolo de Pesquisa}

Invasão da cartilagem tireóide no tumor precoce de andar glótico acometendo a comissura anterior

№:

Nome:

Idade:

Gênero:

Tabagismo: (1) não (2) + (3) ++ (4) +++ (5) ++++

(cada + corresponde a 10 cigarros/dia)

Etilismo: (0) não (1) sim

Sintomas: (1) disfonia, (2) sensação de corpo estranho na garganta, (3) outros Tempo de história (meses):

Acometimento da comissura anterior: (1) lesão acomete a comissura anterior aí se detendo; (2) a lesão ultrapassa a comissura anterior e acomete o terço anterior da prega vocal contra-lateral

Estadiamento clínico do tumor primário: (1) T1b; (2) T2

Tratamento prévio: (0) não, (1) Radioterapia

Tratamento adjuvante: (0) não, (1) Radioterapia, (2) Radio + Quimioterapia Invasão de cartilagem à macroscopia: (1) não, (2) sim

Recidiva: (0) não, (1) sim

Tempo de seguimento (meses):

Status atual: (1) vivo livre de doença; (2) morte por câncer: (3) morte assintomático

\section{Análise Histopatológica:}

Grau de diferenciação do tumor: (1) I; (2) II; (3) III; (4) indiferenciado Acometimento microscópico da cartilagem: (1) há tecido são entre o tumor e a cartilagem; (2) tumor contíguo à cartilagem sem a infiltrar; (3) tumor infiltra a cartilagem; (4) tumor ultrapassa o limite ventral da cartilagem.

Invasão ultrapassa a linha média: (0)não, (1) sim 
REFERÊNCIAS 


\section{Referências}

1. Yeager VL, Archer CR. Anatomical routes for cancer invasion of laryngeal cartilages. Laryngoscope. 1982;92(4):449-52.

2. Bagatella F, Bignardi L. Morphological study of the laryngeal anterior commissure with regard to the spread of cancer. Acta Otolaryngol. 1981;92(1-2):167-71.

3. Bagatella F, Bignardi L. Behavior of cancer at the anterior commissure of the larynx. Laryngoscope. 1983;93(3):353-6.

4. Olofsson J. Specific features of laryngeal carcinoma involving the anterior commissure and the subglottic region. Can $\mathrm{J}$ Otolaryngol. 1975;4(4):618-36 .

5. Olofsson J. Aspects on laryngeal cancer based on whole organ sections. Auris Nasus Larynx. 1985;12 Suppl 2:S166-71.

6. Back G, Sood S. The management of early laryngeal cancer: options for patients and therapists. Curr Opin Otolaryngol Head Neck Surg. 2005;13(2):85-91.

7. Zouhair A, Azria D, Coucke P, Matzinger O, Bron L, Moeckli R, Do HP, Mirimanoff RO, Ozsahin M. Decreased local control following radiation therapy alone in early-stage glottic carcinoma 
with anterior commissure extension. Strahlenther Onkol. 2004;180(2):84-90.

8. Cellai E, Frata P, Magrini SM, Paiar F, Barca R, Fondelli S, Polli C, Livi L, Bonetti B, Vitali E, De Stefani A, Buglione M, Biti G. Radical radiotherapy for early glottic cancer: Results in a series of 1087 patients from two Italian radiation oncology centers. I. The case of T1N0 disease. Int $\mathrm{J}$ Radiat Oncol Biol Phys. 2005;63(5):1378-86.

9. Maheshwar AA, Gaffney CC. Radiotherapy for T1 glottic carcinoma: impact of anterior commissure involvement. J Laryngol Otol. 2001;115(4):298-301.

10. Lohynska R, Slavicek A, Bahanan A, Novakova P. Predictors of local failure in early laryngeal cancer. Neoplasma. 2005;52(6):483-8. 11. Colasanto JM, Haffty BG, Wilson LD. Evaluation of local recurrence and second malignancy in patients with $\mathrm{T} 1$ and $\mathrm{T} 2$ squamous cell carcinoma of the larynx. Cancer J. 2004;10(1):61-6.

12. Sewnaik A, Meeuwis CA, van der Kwast TH, Kerrebijn JD. Partial laryngectomy for recurrent glottic carcinoma after radiotherapy. Head Neck. 2005;27(2):101-7.

13. Mantilla-Morales A, Gallegos-Hernández JF, Posada-Sibaja A. [Histopathologic study of the frontolateral laryngectomy specimen: topics of clinical interest] Estudio histopatológico de la pieza de 
laringectomía frontolateral. Puntos de interés clínico. Cir Cir. 2005;73(4):315-8.

14. Steiner W, Ambrosch P, Rödel RM, Kron M. Impact of anterior commissure involvement on local control of early glottic carcinoma treated by laser microresection. Laryngoscope. 2004;114(8):148591.

15. Goss CM, Gray H. Anatomia. 29a ed. Rio de Janeiro: Guanabara-Koogan; 1977.pp.916-25.

16. Hajek M. Anatomische Unterssuchungen uber das Larynxodem. Arch f. Klin Chir. 1891;42:46-93.

17. Broyles EN. The anterior commissure tendon. Ann Otol Rhinol Laryngol 1943;52:342-345.

18. Pressman J, Dowdy A, Libby R, Fields M. Further studies upon the submucosal compartments and lymphatics of the larynx by the injection of dyes and radioisotopes. Ann Otol. 1956;65(4):963-80.

19. Tucker GF, Smith HR Jr. A histological demonstration of the development of laryngeal connective tissue compartments. Trans Am Acad Ophtalmol Otolaryngol. 1962;66:308-328.

20. Kirchner JA. One hundred laryngeal cancers studies by serial section. Ann Otol Rhinol Laryngol. 1969;78(4):689-709.

21. Olofsson J, van Nostrand AW. Growth and spread of laryngeal and hypopharyngeal carcinoma with reflections on the effect of 
preoperative irradiation. 139 cases studied by whole organ serial sectioning. Acta Otolaryngol Suppl. 1973;308:1-84.

22. Olofsson J, Williams GT, Rider WD, Bryce DP. Anterior commissure carcinoma. Primary treatment with radiotherapy in 57 patients. Arch Otolaryngol. 1972;95(3):230-3.

23. Leroux-Robert J. Indications for radical surgery, partial surgery, radiotherapy and combined surgery and radiotherapy for cancer of the larynx and hypopharynx. Ann Otol Rhinol Laryngol. 1956;65:137-53.

24. Fiorella R, Di Nicola V, Mangiatordi F, Fiorella ML. Indications for frontolateral laryngectomy and prognostic factors of failure. Eur Arch Otorhinolaryngol. 1999;256(8):423-5.

25. Som ML, Silver CE. The anterior commissure technique of partial laryngectomy. Arch Otolaryngol. 1968;87(2):138-45.

26.. Kirchner JA. Cancer at the anterior commissure of the larynx. Results with radiotherapy. Arch Otolaryngol. 1970;91(6):524-5.

27. Jesse RH, Lindberg RD, Horiot JC. Vocal Cord Cancer with Anterior Commissure Extension. The American Journal of Surgery. 1971;122:437-9.

28. Strong MS. Laser excision of carcinoma of the larynx. Laryngoscope. 1975;85(8):1286-9. 
29. Jako GJ, Vaughan CW, Strong MS, Polanyi TG. Surgical management of malignant tumors of the aerodigestive tract with carbon dioxide laser microsurgery. Int Adv Surg Oncol. 1978;1:26584.

30. Vaughan CW. Transoral laryngeal surgery using the CO2 laser: laboratory experiments and clinical experience. Laryngoscope. 1978;88(9 Pt 1):1399-420.

31. Steiner W. Endoscopic therapy of early laryngeal cancer. In: Wigand M, Steiner W, Stell P, eds. Functional partial laryngectomy. Berlin: Springer-Verlag; 1984.163-70.

32. Rucci L, Gammarota L, Borghi Cirri MB. Carcinoma of the anterior commissure of the larynx: I. Embryological and anatomic considerations. Ann Otol Rhinol Laryngol. 1996;105(4):303-8.

33. Paulsen F, Kimpel M, Lockemann U, Tillmann Bernhard. Effects of ageing on the insertion zones of the human vocal fold. J Anat. $2000 ; 196: 41-54$.

34. Krespi YP, Meltzer CJ. Laser surgery for vocal cord carcinoma involving the anterior commissure. Ann Otol Rhinol Laryngol. 1989;98(2):105-9.

35. Motta G, Esposito E, Cassiano B, Motta S. T1-T2-T3 glottic tumors: fifteen years experience with $\mathrm{CO} 2$ laser. Acta Otolaryngol Suppl. 1997;527:155-9. 
36. Peretti G, Nicolai P, Piazza C, Redaelli de Zinis LO, Valentini S, Antonelli AR. Oncological results of endoscopic resections of Tis and T1 glottic carcinomas by carbon dioxide laser. Ann Otol Rhinol Laryngol. 2001;110(9):820-6.

37. Rifai M, Khattab $H$. Anterior commissure carcinoma: Ihistopathologic study. Am J Otolaryngol. 2000;21(5):294-7.

38. Nozaki M, Furuta M, Murakami Y, Izawa $\mathrm{Y}$, Iwasaki N, Takahashi H, Watanabe K. Radiation therapy for T1 glottic cancer: involvement of the anterior commissure. Anticancer Res. 2000;20(2B):1121-4.

39. Persky MS, Lagmay VM, Cooper J, Constantinides M, O'Leary R. Curative radiotherapy for anterior commissure laryngeal carcinoma. Ann Otol Rhinol Laryngol. 2000;109(2):156-9.

40. Peretti G, Nicolai P, de Zinis LOR, Berlucchi M, Bazzana T, Bertoni F. Endoscopic CO2 laser excision for Tis, T1, and T2 glottic carcinomas: Cure rate and prognostic factors. Otolaryngol Head Neck Surg. 2000;123(1):124-31.

41. Eckel HE, Thumfart W, Jungehülsing M, Sittel C, Stennert E. Transoral laser surgery for early glottic carcinoma. Eur Arch Otorhinolaryngol. 2000;257:221-6. 
42. Pradhan SA, Pai PS, Neeli SI, D'Cruz AK. Transoral laser surgery for early glottic cancers. Arch Otolaryngol Head Neck Surg. 2003;129(6):623-5.

43. Pearson BW, Salassa JR. Transoral laser microresection for cancer of the larynx involving the anterior commissure. Laryngoscope. 2003;113(7):1104-12.

44. Martín Villares C, Poch Broto J, Ortega Medina L, González Gimeno MJ, Iglesias Moreno MC, Cogolludo F. [Spread channels of anterior commissure cancer: clinico-pathological study and surgical implications] Vías de diseminación del cáncer de comisura anterior: estudio clínico-patológico e implicaciones quirúrgicas. Acta Otorrinolaringol Esp. 2003;54(1):48-53.

45. Davis RK, Hadley K, Smith ME. Endoscopic vertical partial laryngectomy. Laryngoscope. 2004;114(2):236-40.

46. Eryilmaz A, Akmansu H, Topcu E, Acar A, Korkmaz H. The role of 70-degree telescopic examination during direct laryngoscopic evaluation of laryngeal cancers. Eur Arch Otorhinolaryngol. 2004;261(5):267-9.

47. Nur DA, Oguz C, Kemal ET, Ferhat E, Sülen S, Emel A, Münir K, Ann CS, Mehmet S. Prognostic factors in early glottic carcinoma implications for treatment. Tumori. 2005;91(2):182-7. 
48. Barbosa MM, Araújo VJ, Boasquevisque E, Carvalho R, Romano S, Lima RA, Dias FL, Salviano SK. Anterior vocal commissure invasion in laryngeal carcinoma diagnosis. Laryngoscope. 2005;115(4):724-30.

49. Herranz J, Gavilán J, Vázquez-Barros JC. Carcinoma de comisura anterior. Acta Otorrinolaringol Esp. 2007;58(8):367-70.

50. Celedón CL, Royer MF, Ortúzar LB. Laringectomía parcial en cáncer laríngeo precoz: 25 años de experiencia. Rev Otorrinolaringol Cir Cabeza Cuello. 2008;68:117-23.

51. Sachse F, Stoll W, Rudack C. Evaluation of treatment results with regard to initial anterior commissure involvement in early glottic carcinoma treated by external partial surgery or transoral laser microresection. Head Neck. 2009;31(4):531-7.

52. Tong CC, Au KH, Ngan RKC, Chow SM, Cheung FY, Fu YT, Au JSK, Law SCK. Impact and relationship of anterior commissure and time-dose factor on the local control of T1N0 glottic cancer treated by 6 MV photons. Rad Oncol. 2011;6:53-61.

53. Foucher M, Barnoud R, Buiret G, Pignat JC, Poupart M. Preand posttherapeutic staging of laryngeal carcinoma involving anterior commissure: review of 127 cases. ISRN Otolaryngol. $2012 ; 2012: 1-3$ 
54. Hartl DM, Landry G, Hans S, Marandas P, Casiraghi O, Janot F. Brasnu DF. Thyroid cartilage invasion in early-stage squamous cell carcinoma involving the anterior commissure. Head Neck. 2012;34(10):1476-9.

55. Szyfter W, Leszczyńska $M$, Wierzbicka $M$, Kopeć $T$, Bartochowska A. Value of open horizontal glottectomy in the treatment for T1b glottic cancer with anterior commissure involvement. Head Neck. 2013;35(12):1738-44.

56. Taylor SM, Kerr P, Fung K, Aneeshkumar MK, Wilke D, Jiang Y, Scott J, Phillips J, Hart RD, Trites JR, Rigby MH. Treatment of T1b glottic SCC: laser vs. radiation. A Canadian multicenter study. J Otolaryngol Head Neck Surg. 2013;42:22.

57. Mizrachi A, Rabinovics N, Hilly O, Shvero J. Analysis of failure following transoral laser surgery for early glottic cancer. Eur Arch Otorhinolaryngol. 2014;271:224-51.

58. Milovanovic J, Jotic A, Djukic V, Pavlovic B, Trivic A, KrejovicTrivic S, Milovanovic A, Milovanovic A, Artiko V, Banko B. Oncological and functional outcome after surgical treatment of early glottic carcinoma without anterior commissure involvement. Biomed Res Int. 2014;2014:1-7.

59. Leszczyńska $M$, Tokarski M, Jarmołowska-Jurczyszyn $D$, Kosikowski P, Szyfter W, Wierzbicka M. Adverse histopathological 
findings in glottic cancer with anterior commissure involvement. Eur Arch Otorhinolaryngol. 2015;272(8):1973-81.

60. Mendelsohn AH, Kiagiadaki D, Lawson G, Remacle M. CO2 laser cordectomy for glottic squamous cell carcinoma involving the anterior commissure: voice and oncologic outcomes. Eur Arch Otorhinolaryngol. 2015;272(2):413-8.

61. Wu J, Zhao J, Wang Z, Li Z, Luo J, Liao B, Yang Z, Liu Q, Wang B, Wen W, Lei W. Study of the Histopathologic Characteristics and Surface Morphologies of Glottic Carcinomas With Anterior Vocal Commissure Involvement. Medicine (Baltimore). 2015;94(29):e1169. 62. Ulusan M, Unsaler S, Basaran B, Yılmazbayhan D, Aslan I. The incidence of thyroid cartilage invasion through the anterior commissure in clinically early-staged laryngeal cancer. Eur Arch Otorhinolaryngol. 2016;273:447-53

63. Kitani Y, Kubota A, Furukawa M, Sato K. Prognostic factors for local control in patients receiving radiation therapy for early glottic cancer: anterior commissure involvement and effect of chemoradiotherapy. Eur Arch Otorhinolaryngol. 2016;273(4):1011-7. 64. Edge SB, Byrd DR, Compton CC et al (eds) AJCC cancer staging manual. $7^{\text {th }}$ ed. New York: Springer; 2010.pp.57-62.

65. Masson P. Tumoeurs humaines histologie diagnostic et techniques. $2^{\text {ème }}$ ed. Paris: Maloine; 1956. 
66. Kumar V, Abbas AK, Aster JC. Robbins \& Cotran Patologia. $9^{a}$ ed. Rio de Janeiro: Elsevier Saunders; 2016. Capítulo 7 - Neoplasia. 67. Williamson S. Kidney tumor. Adult malignancies - miscellaneous nuclear grading (Fuhrman). Disponível em: http://www.pathologyoutlines.com/topic/kidneytumormalignantnuclea rgrading.html Acesso em: 12 de outubro de 2016.

68. Kumar V, Abbas AK, Aster JC. Robbins \& Cotran Patologia. $9^{a}$ ed. Rio de Janeiro: Elsevier Saunders; 2016. Capítulo 5 - Doenças do sistema imunológico.

69. Behmer OA, Tolosa EMC, Freitas Neto AG, Rodrigues CJ. Manual de técnicas para histologia normal e patológica. $2^{\underline{a}}$ ed. Barueri: Manole; 2003.

70. Zeitels SM, Hillman RE, Franco RA, Bunting GW. Voice and treatment outcome from phonosurgical management of early glottic cancer. Ann Otol Rhinol Laryngol Suppl. 2002;190:3-20.

71. Al-Mamgani A, van Rooij PH, Woutersen DP, Mehilal R, Tans L, Monserez D, Baatenburg de Jong RJ. Radiotherapy for T1-2N0 glottic cancer: a multivariate analysis of predictive factors for the long-term outcome in 1050 patients and a prospective assessment of quality of life and voice handicap index in a subset of 233 patients. Clin Otolaryngol. 2013;38(4):306-12. 
72. Jackson CL. Primary malignant disease of the larynx. Laryngoscope. 1904;14:590-618.

73. Thomson SC. Intrinsic cancer of the larynx. $\mathrm{Br}$ Med J. 1912;1:355-9.

74. Clerf LH. Cancer of the larynx. An analysis of two hundred and fifty operative cases. Arch Otolaryngol. 1940;32:484-98.

75. Kemler Jl. Bilateral thyrotomy for carcinoma of the larynx. Laryngoscope. 1947;57:704-18.

76. Figi FA. Removal of carcinoma of the larynx with immediate skin graft for repair. Ann Otol Rhinol Laryngol. 1950;59:474-86.

77. Pressman JJ. Cancer of the larynx: latyngoplasty to avoid laryngectomy. Arch Otolaryngol. 1954;59:395-412.

78. Norris CM. Technique of extended fronto-lateral partial laryngectomy. Laryngoscope. 1958;68:1240-50.

79. Conley JJ. Glottic reconstruction and wound rehabilitation. Arch Otolaryngol. 1961;74:2-24.

80. Bouche J, Frech C, Husson Y. L'hemi-laryngectomie avec epiglottoplastie. Ann d'Oto-laryngol (Paris). 1965;82:421-8.

81. Bailey JB. Partial laryngectomy and laryngoplasty: a technique and review. Trans Am Acad Ophtalmol Otolaryngol. 1966;70(4):55974. 
82. Maran AG, Hast MH, Leonard JR. Reconstructive surgery for improved glottic closure and voice following partial laryngectomy: an experimental study. Medline. 1968;78(11):1916-36.

83. Bailey JB. Partial laryngectomy and laryngoplasty. Laryngoscope. 1971;81:1742-71.

84. Quinn HJ. A new technique for glottic reconstruction after partial laryngectomy. Laryngoscope. 1969;79:1980-2011.

85. Ogura JH, Biller HF. Partielle laryngectomie. Archiv fur OhrenNasen und Kehlkopfheilkunde. 1969;194:339-51.

86. Bailey BJ. Glottic reconstruction after hemilaryngectomy: Bipedicle muscles flap laryngosplasty. Laryngoscope. 1975;65:13753.

87. Conley J. Regional skin flaps in partial laryngectomy. Laryngoscope. 1975;85:942-9.

88. Hirano M. Techinique for glottic reconstruction following vertical partial laryngectomy: a preliminary report. Ann Otol Rhinol Laryngol. 1976;85:25-31.

89. Park NH, Major Wj, Sauers PL. Hemilaryngectomy and vocal cord reconstruction with digastric tendon graft. Surg Gynecol Obstet. 1982;155:253-6. 
90. Calcaterra TC. Sternohyoid myofascial flap reconstruction of the larynx for vertical partial laryngectomy. Laryngoscope. 1983;93:4224.

91. Mohr RM, Quenelle DJ, Shumrick DA. Vertical-frontolateral laryngectomy (hemilaryngectomy). Arch Otolaryngol. 1983;109:38495.

92. Brasil OC, Pontes PA. Laringectomias parciais verticais: reconstrução com retalho miocutâneo de platisma. Rev Paul Med. 1990;108(5):213-20.

93. Olsen KD, DeSanto LW. Partial vertical laryngectomy-indications and surgical technique. Am J Otolaryngol. 1990;11:153-60.

94. Thomas JV, Olsen KD, Neel B, Desanto LW, Suman VJ. Early glottic carcinoma treated with open laryngeal procedures. Arch Otolaryngol Head Neck Surg. 1994;120:264-8.

95. Vega SF, Scola B, Vega MF, Martinez T, Scola E. Chirurgia verticale della laringe. Técnica chirurgica. Resultati oncologici e funzionali. Acta Otorhinol Ital. 1996;16:272-80.

96. Sheen TS, Ko JY, Chang YL. Parcial vertical laryngectomy in the treatment of early glottic cancer. Ann Otol Rhinol Laryngol. 1998;107:593-7.

97. Sennes LU, De La Cortina RAC, Tsuji DH, Ugadin HK, Romano FR, Imamura R. Tratamento cirúrgico dos carcinomas glóticos 
invasivos iniciais (T1 e T2). Rev Bras Otorrinolaringol. 2000;66:2438.

98. Giovanni A, Guelfucci B, Gras R, Yu P, Zanaret M. Partial frontolateral laryngectomy with epiglottic reconstruction for management of early-stage glottic carcinoma. Laryngoscope. 2001;111(4 Pt 1):663-8.

99. Zeitels SM, Dailey SH, Burns JA. Technique of en block laser endoscopic frontolateral laryngectomy for glottic cancer. Laryngoscope. 2004;114(1):175-80.

100. Cruz WP, Dedivitis RA, Rapoport A, Guimarães AV. Videolaryngostroboscopy following frontolateral laryngectomy with sternohyoid flap. Ann Otol Rhinol Laryngol. 2004;113(2):124-7. 101. Brumund KT, Gutierrez-Fonseca R, Garcia D, Babin E, Hans S, Laccourreye O. Frontolateral vertical partial laryngectomy without tracheotomy for invasive squamous cell carcinoma of the true vocal cord: a 25-year experience. Ann Otol Rhinol Laryngol. $2005 ; 114(4): 314-22$.

102. Gilbert RW, Neligan PC. Microsurgical laryngotracheal reconstruction. Clin Plast Surg. 2005;32(3):293-301. 